\section{DYNAMIC EFECTIVE THICKNESS IN LAMINATED-GLASS BEAMS AND PLATES}

\author{
M. López-Aenlle ${ }^{\mathrm{a}^{*}}$, F. Pelayo ${ }^{\mathrm{a}}$ \\ ${ }^{a}$ Department of Construction and Manufacturing Engineering, University of \\ Oviedo, Campus de Gijón, Zona Oeste, Edificio 7, 33203, Gijón, Spain. \\ "corresponding author; E-mail: aenlle@uniovi.es \\ Phone: +34985 182057, Fax: +34985 182433
}

\begin{abstract}
In recent years, several equations have been proposed to calculate deflections and stresses in laminated-glass beams and plates under static loading using the concept of effective thickness, which consists of calculating the thickness of a monolithic element with equivalent bending properties to a laminated element. Recently, an effective thickness for the dynamic behaviour of laminated-glass beams has been proposed to enable the modal parameters (natural frequencies, loss factors and mode shapes) to be determined using an equivalent monolithic model. In the present paper, the technique has been extended to the two-dimensional case of rectangular laminated-glass plates and the steps needed to estimate the modal parameters of laminated-glass elements using this methodology are presented. The dynamic effective thickness concept has been validated by experimental tests made on a laminated-glass beam and a laminated-glass plate. The results show that good accuracy is achieved in the natural frequencies and mode shapes but high scatter is encountered in the loss factors.
\end{abstract}

Keywords: A. Laminated glass ; B. Operational Modal Analysis ; C. Effective Thickness; D. Viscoelasticity. 


\section{NOMENCLATURE}

D

E

$E_{\text {eff }}$

$E_{1}$

$E_{3}$

$E I^{*}$

$E_{2}^{*}(\omega)$

$E^{\prime}(\omega) \quad$ Real component of the tensile complex modulus (storage)

$E^{\prime \prime}(\omega) \quad$ Imaginary component of the tensile complex modulus (loss)

$E I_{T} \quad E_{1} I_{1}+E_{3} I_{3}$

$E_{2}(t) \quad$ Viscoelastic relaxation tensile modulus for polymeric interlayer

$E_{\infty}^{2} \quad$ Equilibrium tensile modulus for the polymeric interlayer

$G_{2}(t) \quad$ Viscoelastic relaxation shear modulus for the polymeric interlayer

$G_{2}^{*}(\omega) \quad$ Complex shear modulus for the polymeric interlayer

$G_{0} \quad$ Glassy shear modulus

$H_{1} \quad$ Thickness of glass layer 1 in laminated glass

$H_{2} \quad$ Thickness of polymeric layer in laminated glass

$H_{3} \quad$ Thickness of glass layer 3 in laminated glass 
$H_{0} \quad H_{2}+\left(\frac{H_{1}+H_{3}}{2}\right)$

I

Second moment of area

$I_{1} \quad \frac{H_{1}^{3}}{12}$

$I_{3} \quad \frac{H_{3}^{3}}{12}$

$I_{T} \quad I_{1}+I_{3}=\frac{H_{1}^{3}+H_{3}^{3}}{12}$

$K(t) \quad$ Viscoelastic bulk modulus

L Length of a glass beam

T Temperature

$T_{0} \quad$ Reference temperature

$Y \quad \frac{H_{0}^{2} E_{1} H_{1} E_{3} H_{3}}{E I_{T}\left(E_{1} H_{1}+E_{3} H_{3}\right)}$

$Y_{1} \quad \frac{12 H_{0}^{2} H_{1} H_{3}}{\left(H_{1}^{3}+H_{3}^{3}\right)\left(H_{1}+H_{3}\right)}$

\section{LOWERCASE LETTERS}

$a_{T} \quad$ Shift factor

$b \quad$ Width of a glass beam

$e_{i} \quad$ Modulus coefficient in Prony's series viscoelastic model

$g(x) \quad$ Shape function (Galuppi and Royer Carfagni model)

$g_{M}^{*} \quad$ Shear parameter M\&Ms Model 
Shear parameter RKU model

Imaginary unit

Wavenumber

Complex wave number

Mass per unit area

Time

w

Deflection

\section{GREEK LETTERS}

$\Omega^{*}$

Non-dimensional complex frequency

$\beta$

Bucking ratio for a beam

$\zeta$

Modal damping ratio

$\eta$

Loss factor

$\eta_{2} \quad$ Loss factor of the polymeric interlayer of laminated glass

$v_{i} \quad$ Poisson ratio of the i-th glass layer

$\rho_{i} \quad$ Mass density of the i-th glass layer

$\tau_{i} \quad$ Time coefficient in Prony's series viscoelastic model

$\omega$

Frequency 


\section{INTRODUCTION}

Laminated glass is a sandwich or layered material consisting of two or more plies of monolithic glass with one or more interlayers of a polymeric material. Thus, a laminated-glass element (beam, plate, etc.) is a composite material which combines the properties of the glass with the benefits of a highly elastic polymeric material, i.e. the structural behaviour of laminated glass is that of a composite structure. The glass layers may be either normal annealed, heat-strengthened, chemically strengthened or tempered glass. When the cross-section is made of different glasses (e.g. one layer of annealed glass and the other of tempered glass) it is called a hybrid laminated-glass element. However, the treatments affect the ultimate strength but not the Young modulus, and therefore no distinction is made concerning the type of glass if the calculations are made prior to glass breakage. All polymeric interlayers are viscoelastic in nature [1], i.e. their mechanical properties are frequency (or time) and temperature dependent. Polyvinyl butyral (PVB) is the most commonly used interlayer material and is marketed in thicknesses of $0.38 \mathrm{~mm}$ or a multiple of this value $(0.76 \mathrm{~mm}, 1.12 \mathrm{~mm}, 1.52 \mathrm{~mm})$. However, the new ionoplastic interlayers improve the mechanical properties of laminated glass and maintains a significant advantage (higher stiffness and strength) over the PVB for a large range of temperatures [1]. This interlayer material is now in flat sheet form, in thicknesses of $0.89,1.52,2.27$, and $3.05 \mathrm{~mm}$, and as rolled sheeting, at $0.89 \mathrm{~mm}$ thickness. The simplest laminated-glass configuration consists of three layers: two monolithic glass plies and a polymeric core (see Fig. 1).

The response of laminated-glass elements varies between two borderlines [2]: 1) The layered limit corresponding to the case when the beam consists of free-sliding glass plies and 2) the monolithic limit, when the Euler-Bernoulli assumptions hold (plane sections remain plane) for the entire section of the laminated-glass element (the response of the composite beam approaches that of a homogeneous glass beam with an equal cross-section) [3-4]. As the tensile modulus of the PVB is far less in comparison with that corresponding to glass, significant transverse shear appears in the viscoelastic layer $[1,8,10]$. 
In the analytical and numerical models, glass mechanical behaviour is usually modeled as linear-elastic prior to glass breakage, whereas the polymeric interlayer is characterized as linear-viscoelastic. Laminated glass is easy to assemble in a finiteelement model but many small 3D elements are needed to mesh accurately, which, on the other hand, are very high time consuming. In the last few years, some papers have been published on the calculation of laminated-glass elements, examining the concept of effective thickness $[1,3,4,8]$. The method consists of calculating the thickness of a monolithic element with bending properties equivalent to those of the laminated one. The effective thickness can then be used in analytical equations and simplified finiteelement models instead of the laminated-glass element [9].

The aim of the present paper is to propose a simplified method to estimate the modal parameters of rectangular laminated-glass plates while avoiding the use of finiteelement models or complicated analytical models. The method is based on the dynamic effective thickness proposed in a previous paper [9] for laminated-glass beams, which is here extended to the two-dimensional case of rectangular laminated-glass plates. An alternative to the effective thickness is the concept of effective Young modulus, which can be used interchangeably for laminated-glass elements with the same accuracy. This technique can be applied to three-layered laminated-glass plates with glass showing a linear elastic behaviour and the polymeric core showing viscoelastic behaviour. Thus the glass layers can be made of different types of glass (annealed, tempered, heatstrengthened, etc.), and the traditional cores (PVB, ionoplastic, etc.) can be considered in this model. In this paper, the modal parameters (natural frequencies, loss factors, and mode shapes) of a $1400 \times 1000 \times 16 \mathrm{~mm}$ laminated-glass plate pin-supported at the four corners, and of a beam $1 \mathrm{~m}$ long and $12 \mathrm{~mm}$ thick, both the beam and the plate with annealed glass plies and PVB core, were estimated using the effective thickness concept. For the validation of the model, operational modal tests were performed on the beam and the plate, and the modal parameters identified from the experimental responses were compared with those predicted using the effective thickness concept. 


\section{STATE OF THE ART}

\subsection{Viscoelastic Behaviour}

The mechanical properties of a linear-viscoelastic material are frequency (or time) and temperature dependent [11]. In the frequency domain, the complex tensile modulus, $E_{2}^{*}(\omega)$, at temperature $T$ is given by:

$E_{2}^{*}(\omega, T)=E_{2}^{\prime}(\omega, T)+i \cdot E_{2}^{\prime \prime}(\omega, T)=E_{2}^{\prime}(\omega, T)\left(1+i \cdot \eta_{2}(\omega, T)\right)$

where superscript ' $*$ ' indicates complex, $\omega$ represents the frequency, $i$ is the imaginary unit, $E_{2}^{\prime}(\omega, T)$ and $E_{2}^{\prime \prime}(\omega, T)$ are the storage and the loss tensile moduli, respectively, and

$\eta_{2}(\omega)=\frac{E_{2}^{\prime \prime}(\omega, T)}{E_{2}^{\prime}(\omega, T)}$

is the loss factor that relates the two moduli. The subscript ' 2 ' is used hereafter to reference the viscoelastic interlayer.

With regard to the shear behavior, the complex shear modulus, $G_{2}^{*}(\omega, T)$, is given by:

$G_{2}^{*}(\omega, T)=G_{2}^{\prime}(\omega, T)+i \cdot G_{2}^{\prime \prime}(\omega, T)=G_{2}^{\prime}(\omega, T)\left(1+i \cdot \eta_{2}(\omega, T)\right)$

where $G^{\prime}(\omega, T)$ and $G^{\prime \prime}(\omega, T)$ are the storage and the loss shear moduli, respectively.

Both the shear and tensile moduli can be related by means of the correspondence principle $[12,13]$, introducing the corresponding complex viscoelastic properties, i.e.: 
$G_{2}^{*}(\omega, T)=\frac{3 E_{2}^{*}(\omega, T) K_{2}^{*}(\omega, T)}{9 K_{2}^{*}(\omega, T)-E_{2}^{*}(\omega, T)}$

where $K_{2}^{*}(\omega, T)$ is the complex bulk modulus.

For the temperature dependence of the viscoelastic interlayer properties to be taken into account, a simply thermo-rheological behavior in the material is commonly assumed [14]. This enables a relation between time and temperature to be determined in linear viscoelastic materials using a Time-Temperature-Superposition (TTS) model such as the William-Landel-Ferry or Arrhenius equations $[14,15,16]$. Once the TTS model is fitted for a reference temperature, $T_{0}$, i.e. the temperature used in the experimental tests, the moduli for the material to a different temperature, $T_{1}$, can be estimated by shifting in time the moduli at temperature $T_{0}$ using a shift factor, $a_{T}\left(T_{0}, T_{1}\right)$, established from the material TTS model. A similar process can be followed in the frequency domain [14, $16]$.

To simplify the expressions in the text, we hereafter assume that the moduli for the interlayer have been previously calculated for the temperature of interest, so that only the frequency or time dependence of the viscoelastic interlayer will be taken into account in the expressions presented.

The mechanical performance of a viscoelastic material can be established by relaxation or creep tests in the time domain $[14,15]$. The relaxation master curve, $E_{2}(t)$, is usually fitted with a generalized Maxwell model [16], which can be represented with a Prony series given by:

$E_{2}(t)=E_{2}^{\infty}+\sum_{i=1}^{n} e_{i} \mathrm{e}^{\left(-\frac{t}{\tau_{i}}\right)}$ 
where $e_{i}$ and $\tau_{i}$ are the Prony series coefficients to be estimated and $E_{\infty}$ is the equilibrium modulus. The store and loss components of the complex modulus can be determined directly from the relaxation Prony series coefficients by:

$E_{2}^{\prime}(\omega)=E_{2}^{\infty}+\sum_{i=1}^{n} \frac{\tau_{i}^{2} \omega^{2} e_{i}}{1+\tau_{i}^{2} \omega^{2}}$

and

$E_{2}^{\prime \prime}(\omega)=E_{2}^{\infty}+\sum_{i=1}^{n} \frac{\tau_{i} \omega e_{i}}{1+\tau_{i}^{2} \omega^{2}}$

Expressions similar to Eqs. $(5,6$, and 7$)$ can be used to determine the complex shear moduli from shear relaxation data.

The viscoelastic mechanical properties can also be determined by dynamic tests in the frequency domain $[14,15]$.

In this work, the complex shear modulus $G_{2}^{*}(\omega)$ and the complex tensile modulus $E_{2}^{*}(\omega)$ of the PVB interlayer at $T_{0}=20^{\circ} \mathrm{C}$, shown in Figure 2, were considered [9]. The coefficients of the Willian-Landel-Ferry equation at $T_{0}=20^{\circ} \mathrm{C}$ are $C_{1}=12.60$ and $C_{2}=74.46$.

\subsection{Assumptions}

The model proposed in this paper for the dynamic behaviour of laminated-glass plates considers the following assumptions:

- The glass layers exhibit linear-elastic behavior up to the first cracking and they carry both bending stress and shear stress. On the other hand, the contribution of the shear to the deflection is neglected. Thus, the glass behavior can be modeled by means of the Young modulus and the Poisson ratio [5- 6, 17-28]. 
Although the glass behavior is assumed to be linear elastic, the entire section of a laminated-glass element does not behave according to the Euler Bernoulli assumptions (plane sections remain plane) and the normal stresses follow the typical linear zigzag distribution through the thickness $[25,26,28]$.

- There is no slipping between the elastic and viscoelastic layers at their interfaces, i.e. the face layers and the interlayer are well bonded [17, 25-32].

- The interlayer carries transverse shear stress and undergoes shear strain but the longitudinal stresses are negligible. Thus, the behavior of the interlayer is modeled by means of the shear modulus $G_{2}(t)$ in the time domain or $G_{2}^{*}(\omega)$ in the frequency domain $[5-6,17-28]$.

- The ultimate strain of the interlayer is far greater than that of the glass plies. [17, 25- 29, 32-34].

- The interlayer exhibits a linear-viscoelastic behavior [18, 19, 20, 21, 22, 23, 24] described by the shear modulus $G_{2}(t, T)$ or $G_{2}^{*}(\omega, T)$. This implies that all the variables considered in the model (stiffness, deflections, stresses, effective thicknesses, etc.) are time or frequency and temperature dependent.

However, some analytical models describe the viscoelastic behavior of the interlayer by an elastic behavior with parameters that depend on the loading duration and temperature 17, 25-27, 35];

- The normal stresses $\sigma_{z}$ in the direction perpendicular to the plate can be disregarded in both the glass plies and the interlayer. This assumption leads to the idea that the three layers have the same transversal displacement, $w(x, \omega)$ or $w(x, t)[27,29]$.

- The deflections of the plate are minor, i.e. the effects of geometric non-linearity are neglected [25, 26, 27, 28]

An extensive explanation of the assumptions considered in the analytical models for laminated-glass elements can be seen in [17]. 


\subsection{Analytical models for the static response of laminated-glass beams}

In recent years, several models have been proposed for calculating deflections and stresses in laminated-glass beams under static loadings.

Asik and Tezcan [7] derived three coupled non-linear differential equations for analyzing laminated-glass beams which are valid for beams with different boundary conditions. An analytical solution to the differential equations is presented for the case of simply supported beams.

Ivanov [5] designed a simple mathematical model where the simple bending theory is applicable for the single glass layers and the effect of the shear of the PVB-interlayer is described by an additional differential equation.

Koutsawa and Daya [6] developed a mathematical model for the displacement, strain, and stress fields of laminated-glass beams on viscoelastic supports, which are modeled by two springs (rotational, $K_{R}$, and translational, $K_{T}$ ), on each extremity of the beam. The model is validated for the case of the simply supported beam, which is a particular case of the general model, assigning $K_{R}=0$ and $K_{T}=\infty$.

Foraboschi [35] developed a mathematical model for determining the critical load, on laminated-glass beams subjected to compressive loads and provides a closed-form expression to calculate the critical load. The paper also provides rules in order to use laminated glass for compressive elements.

\subsubsection{The model of Benninson et al.}

Benninson et al. $[1,8]$ have proposed a model for the static calculation of laminatedglass elements based on a previous work by Wölfel [36], who proposed a model for a sandwich structure composed of three layers, the outer ones with considerable axial stiffness but negligible bending stiffness, while the inner layer can bear shear stress with only zero axial and flexural strength. Benninson et al. [1] and Calderone et al. [8] have extended Wölfel's approach specifically for the case of laminated glass. For the deflection of the laminated-glass beam, this model assumes a curve similar in type to that corresponding to a simply supported beam under uniformly distributed loading, and 
these assumptions are valid for statically determined composite beams, for which the bending stiffness of the composite plies is negligible. According to Benninson et al. [1] and Calderone et al. [8], the stiffness of the entire laminated-glass beam is given by the equation:

$E I(t)_{S}=E_{1} I_{T}\left(1+\Gamma_{S}(t) Y_{1}\right)$

Where:

$$
\Gamma_{S}(t)=\frac{1}{1+\gamma \frac{E_{1} H_{1} H_{2} H_{3}}{G_{2}(t)\left(H_{1}+H_{3}\right) L^{2}}}
$$

The subindex ' $\mathrm{s}$ ' indicates static, and $\gamma$ is a scalar which depends on the boundary conditions [8]. The parameter $\Gamma_{\mathrm{S}}(\mathrm{t})$ takes values in the range $0 \leq \Gamma_{\mathrm{S}}(\mathrm{t}) \leq 1$ corresponding $\Gamma_{\mathrm{S}}=0$ to the case of a layered beam $\left(G_{2}=0\right)$ and $\Gamma_{S}=1$ to a monolithic beam $\left(G_{2}=\infty\right)$.

This model was originally derived under the assumption that the glass plies have the same Young modulus, i.e. $E_{1}=E_{3}$. However, it can easily be extended to hybrid laminated-glass beams with $E_{1} \neq E_{3}$ by means of:

$E I(t)_{S}=E I_{T}\left(1+\Gamma_{S}(t) Y\right)$

where

$$
\Gamma_{S}(t)=\frac{1}{1+\gamma \frac{E_{1} H_{1} H_{2} E_{3} H_{3}}{G_{2}(t)\left(E_{1} H_{1}+E_{3} H_{3}\right) L^{2}}}
$$


This model provides good results in simply supported beams but can provide only approximate results with other boundary conditions. However, it has the advantage that the equations are simple and easy to use.

\subsubsection{The model of Galuppi and Royer Carfagni}

Galuppi and Royer-Carfagni [3], based upon a variational approach, developed a model for calculating the deflection of laminated-glass beams under static loading that can be applied to a very wide range of boundary and loading conditions. The deflection of the beam is given by:

$w(x, t)=-\frac{g(x)}{E I(t)_{S}}$

where $\mathrm{g}(\mathrm{x})$ is a shape function that takes the form of the elastic deflection of a monolithic beam having a constant cross-section under the same loading and boundary conditions as the laminated-glass beam, and $E I(t)_{S}$ is the bending stiffness of the laminated-glass beam given by:

$E I(t)_{S}=\frac{E_{1}}{\frac{\eta_{S 1}(t)}{I_{\text {tot }}}+\frac{1-\eta_{S 1}(t)}{I_{1}+I_{3}}}$

where

$I_{\text {tot }}=I_{1}+I_{3}+\frac{H_{1} H_{3}}{H_{1}+H_{3}} H_{0}^{2}=I_{T}\left(1+Y_{1}\right)$

and

$\eta_{S 1}(t)=\frac{1}{1+\frac{I_{1}+I_{3}}{I_{\text {tot }}} \frac{E_{1}}{\mathrm{G}_{2}(t)} \frac{H_{2} H_{1} H_{3}}{H_{1}+H_{3}} \psi_{B}}$

The coefficient $\psi_{B}$ depends on the geometry of the beam and on its boundary and loading conditions [3]. The values for the most practical cases are tabulated in [37]. 
If Eq. (14) is substituted in Eq. (15), it becomes:

$$
\eta_{S 1}(t)=\frac{1}{1+\frac{E_{1}}{\mathrm{G}_{2}(t)} \frac{H_{2} H_{1} H_{3}}{\left(H_{1}+H_{3}\right)\left(1+Y_{1}\right)} \psi_{B}}
$$

The parameter $\eta_{S 1}(t)$ takes values in the range $0 \leq \eta_{S 1}(t) \leq 1$ corresponding $\eta_{S 1}=0$ to the case of a layered beam and $\eta_{S 1}=1$ to a monolithic beam.

The identification of Eq. (8) and Eq. (15) gives:

$\psi_{B}=\gamma / L^{2}$

This model can also be extended to hybrid laminated-glass beams $\left(E_{1} \neq E_{3}\right)$ with the expressions:

$$
\operatorname{EI}(t)_{S}=\frac{1}{\frac{\eta_{S}(t)}{E I_{T}(1+Y)}+\frac{1-\eta_{S}(t)}{E I_{T}}}
$$

where

$$
\eta_{S}(t)=\frac{1}{1+\frac{E_{1} H_{1} H_{2} E_{3} H_{3}}{(1+\mathrm{Y}) \mathrm{G}_{2}(t)\left(E_{1} H_{1}+E_{3} H_{3}\right)} \psi_{B}}
$$

\subsection{Analytical models for the static response of laminated-glass plates}

Foraboschi [17] has proposed a model for the static response of laminated-glass plates with thin and soft interlayer which consists of a system of three analytical equations, derived from the Kirchhoff-Love assumptions for thin plates with small deflections, and a solution for a rectangular simply supported plate under uniformly distributed static loading is provided. However, the model can be applied to different shapes, 
boundary conditions, and loadings, using proper boundary conditions and a mathematical form of the series for the loading and the solution.

An analytical model for a sandwich plate with a soft interlayer of any thickness was derived by Foraboschi [26]. An exact solution for laminated-glass plates with an interlayer of any thickness and any transverse elasticity modulus was proposed by Foraboschi [29].

In the models [17, 26 and 29] the viscoelastic behaviour of the interlayer is modeled in a linear elastic manner by means of the shear modulus $G_{2}$ provided that it is related to the temperature and duration of the loading.

\subsubsection{The model of Galuppi and Royer Carfagni.}

Galuppi and Royer-Carfagni [4] have extended the model for beams [3] to the twodimensional case of a rectangular laminated-glass plates under uniform pressure with different boundary configurations at the borders. They have considered the deflection of the plate as:

$w(x, y, t)=-\frac{g(x, y)}{D(t)_{S}}$

where $\mathrm{g}(\mathrm{x}, \mathrm{y})$ is a shape function that takes the form of the elastic deflection of a monolithic plate with constant cross-section under the same loading and boundary conditions. The shape function $\mathrm{g}(\mathrm{x}, \mathrm{y})$ is approximated by the first term of the series expansion for the deflection surface of a monolithic plate. The flexural stiffness $D(t)_{S}$ is expressed as:

$D(t)_{S}=\frac{1}{\left(\frac{\eta_{S P}(t)}{D_{t o t}}+\frac{1-\eta_{s p}(t)}{D_{1}+D_{3}}\right)}$

where: 
$D_{\text {tot }}=D_{1}+D_{3}+\frac{12 D_{1} D_{3}}{D_{1} H_{3}^{2}+D_{3} H_{1}^{2}} H_{0}^{2}$

and

$$
\eta_{s p}(t)=\frac{1}{1+\frac{H_{2}\left(D_{1}+D_{3}\right)}{\mathrm{G}_{2}(\mathrm{t}) D_{t o t}} \cdot \frac{12 D_{1} D_{3}}{D_{1} H_{3}^{2}+D_{3} H_{1}^{2}} \psi_{P}}
$$

and the subindex “p” indicates plate.

Again, the coefficient $\psi_{P}$ depends on the geometry of the plate and on its boundary and loading conditions and their values for the most common practical cases are tabulated in [37].

Eq. (21) can also be expressed as:

$$
D(t)_{S}=\frac{1}{\left(\frac{\eta_{S P}(t)}{\left(D_{1}+D_{3}\right)\left(1+Y_{P}\right)}+\frac{1-\eta_{s p}(t)}{D_{1}+D_{3}}\right)}
$$

where

$$
Y_{P}=\frac{H_{0}^{2} \frac{E_{1} H_{1}}{\left(1-v_{1}^{2}\right)} \frac{E_{3} H_{3}}{\left(1-v_{3}^{2}\right)}}{\left(D_{1}+D_{3}\right)\left(\frac{E_{1} H_{1}}{\left(1-v_{1}^{2}\right)}+\frac{E_{3} H_{3}}{\left(1-v_{3}^{2}\right)}\right)}
$$

If $E_{1}=E_{3}$ and $v_{1}=v_{3}$ it is inferred from eq. (25) that $Y_{P}=Y=Y_{1}$. 


\subsection{Analytical models for the dynamic response of laminated-glass beams}

In the $1960 \mathrm{~s}$ and $70 \mathrm{~s}$, several models were proposed about the dynamic flexural vibration of sandwich beams with viscoelastic core. Ross, Ungar, and Kerwin, the first to study the flexural vibration of a sandwich configuration $[18,19]$, proposed an effective complex flexural stiffness which can be used to determine the modal parameters of a sandwich beam using the equations and the wavenumbers corresponding to an Euler-Bernoulli beam. DiTaranto [20,21] and Mead and Markus $[22,23]$ demonstrated that the flexural motion of a sandwich beam is governed by a sixth-order linear homogeneous differential equation. Rao derived a similar equation of motion using Hamilton's principle [24].

\subsubsection{The model of Mead and Markus (M\&M)}

Mead and Markus [23, 24] formulated a sixth-order differential equation that governs the flexural wave motion of a three-layered constrained-layer damping beam when it vibrates freely at frequency $\omega$, which is given by:

$E I_{T}\left(w^{V I}(x)-g_{M}^{*}(\omega)(1+Y) w^{I V}(x)\right)-\omega^{2} \bar{m}\left(w^{I I}(x)-g_{M}^{*}(\omega) w(x)\right)=0$

where the term $\bar{m}$ is the mass per unit area i.e.:

$\bar{m}=\left(\rho_{1} H_{1}+\rho_{2} H_{2}+\rho_{3} H_{3}\right)$

$g_{M}^{*}$ is a shear parameter given by:

$g_{M}^{*}(\omega)=\frac{G_{2}^{*}(\omega) L^{2}}{H_{2}} \frac{\left(E_{1} H_{1}+E_{3} H_{3}\right)}{E_{1} H_{1} E_{3} H_{3}}$

and the superindex “*” indicates complex.

Eq. (26) yields the following polynomial equation: 
$\left(k_{M}^{*} L\right)^{6}-g_{M}^{*}(\omega)(1+Y)\left(k_{M}^{*} L\right)^{4}-\Omega^{* 2}\left(k_{M}^{*} L\right)^{2}+\Omega^{* 2} g_{M}^{*}=0$

Where $k_{M}^{*}=k_{R}+i \cdot k_{I}$ is the complex wavenumber and $\Omega^{*}$ is a non-dimensional complex frequency defined by [21-24]:

$\Omega^{* 2}=\frac{\omega^{* 2} \bar{m} L^{4}}{E I_{T}}$

The complex Eq. (29), together with the sixth-order characteristic determinant formed using appropriate boundary conditions in Eq. (26), provides the three complex pairs of $k_{M}^{*}$, the complex mode shapes and the complex non-dimensional resonance frequency $\Omega^{*}[22,23]$. If Eq. (29) is substituted in Eq. (30) the natural frequency, $\omega$, and loss factor, $\eta$, are given by :

$$
\omega^{* 2}=\omega^{2}(1+i \cdot \eta)=\frac{k_{M}^{* 4}}{\bar{m}} E I_{T}\left(\frac{\left(k_{M}^{*} L\right)^{2}-g_{M}^{*}(\omega)(1+Y)}{\left(k_{M}^{*} L\right)^{2}-g_{M}^{*}(\omega)}\right)
$$

\subsubsection{The model of Ross, Kerwin and Ungar (RKU)}

Ross, Ungar, and Kerwin [18, 19] developed a model for the flexural vibrations of sandwich elements considering the beam simply supported and assuming a flexural deformation spatially sinusoidal in shape. With these assumptions the equation of motion is formulated as:

$E I^{*}(\omega) w(x, t)^{I V}+\bar{m} \ddot{w}(x, t)=0$

where $E I^{*}(\omega)$ is an effective complex flexural stiffness given by: 


$$
\begin{array}{r}
E I^{*}(\omega)=E I_{T}\left(1+\frac{Y g_{R}^{*}(\omega)\left(1+\frac{E_{3} H_{3}}{E_{1} H_{1}}\right)}{1+g_{R}^{*}(\omega)\left(1+\frac{E_{3} H_{3}}{E_{1} H_{1}}\right)}\right) \\
=E I_{T}\left(1+\frac{Y}{1+\frac{E_{1} H_{1}}{g_{R}^{*}(\omega)\left(E_{1} H_{1}+E_{3} H_{3}\right)}}\right)
\end{array}
$$

$\mathrm{g}_{\mathrm{R}}^{*}(\omega)$ is a shear parameter:

$g_{R}^{*}(\omega)=\frac{G_{2}^{*}(\omega)}{E_{3} H_{3} H_{2} k_{I}^{2}}$

and $k_{I}$ is the wavenumber.

The complex natural frequencies are estimated with the expression:

$\omega^{* 2}=\omega^{2}(1+i \cdot \eta)=k_{I}^{4} \frac{E I^{*}(\omega)}{\bar{m}}$

where $\bar{m}$ is the mass per unit length (Eq. 27).

\subsection{Analytical models for the dynamic response of laminated-glass plates}

Some models have been proposed in the past for sandwich plates with elastic faces and elastic core. Wang [38] has derived an exact relationship between the natural frequencies of a simply supported rectangular sandwich plate and those corresponding to a monolithic Kirchhoff plate with the same geometry and boundary conditions. It is assumed in the model that the variation of the in-plane displacement through the thickness is linear and that the behaviour of faces and core is linear elastic. Thus, exact 
sandwich plate solutions can be arrived at if the solution of the Kirchhoff plate is also exact. Modification factors can be used in the formulas to consider other boundary conditions. However, the damping cannot be predicted with this model.

\subsubsection{The model of Nashif et al.}

The natural frequencies of a rectangular monolithic plate can be estimated by means of the equation [39]:

$\omega^{2}=K_{I}^{4} \frac{D}{\rho H}$

where $k_{I}$ is the wave number, $\rho$ the mass density, $H$ the thickness of the plate and $D$ is the flexural stiffness given by:

$D=\frac{E H^{3}}{12\left(1-v^{2}\right)}$

with $v$ being the Poisson ratio.

Nashif et al. [40] proposed to extend the RKU model for beams (Section 2.4.2) to the two-dimensional case of rectangular laminated-glass plates. Under the same assumptions as those considered for beams, the natural frequencies and loss factor of a rectangular laminated-glass plate can be predicted with:

$\omega^{2}(1+i \eta)=\mathrm{k}_{\mathrm{I}}^{4} \frac{D_{N a s}^{*}(\omega)}{(\rho H)_{e q}}$

Where $(\rho H)_{e q}$ is the mass per unit area: 
$(\rho H)_{e q}=\rho_{1} H_{1}+\rho_{2} H_{2}+\rho_{3} H_{3}$

$D_{\text {Nas }}^{*}(\omega)$ is the complex effective stiffness which is expressed as:

$D_{\text {Nas }}^{*}(\omega)=\frac{E I^{*}(\omega)}{\left(1-v^{* 2}\right)}$

And the subindex “Nas" refers to Nashif.

In Eq. (40) $E I^{*}(\omega)$ is the effective stiffness given by Eq. (33) and $v^{*}$ is the complex effective Poisson ratio but no expressions for $v^{*}$ are proposed by the authors [40].

\subsection{Effective thickness}

The concept of effective thickness for simplifying the calculations of laminated-glass elements under static loading was firstly proposed by Benninson et al. [1,8]. The static deflection-effective thickness is defined as the (constant) thickness of a monolithic glass with the same width and length, which gives the same displacement as does the laminated-glass beam under the same loading $[1,8]$. As the behavior of the laminatedglass elements are time and temperature dependent, an effective thickness has to be determined for each time and temperature.

The effective deflection thickness is derived from the stiffness of the laminated-glass beam and consequently the stiffness given by Eqs. (10) and (18) can be considered effective stiffness. This also means that an effective Young modulus can easily be derived using the same technique which, on the other hand, is more appealing for use in numerical and analytical models - that is, the monolithic model has constant thickness whereas a time- or frequency-dependent Young modulus is defined.

The same concept can be used to determine stresses in laminated-glass elements with the particularity that different effective thicknesses need to be determined for each of the glass plies at each section. If the goal is the maximum stress, the stress-effective 
thickness of a laminated-glass beam ply is defined as the (constant) thickness of a monolithic glass beam that, under the same boundary and load conditions of the problem at hand, presents the same maximum stress $[1,3,8]$. Thus, an effective thickness has to be determined for each of the glass layers.

If we are interested in the stress distribution (the typical zigzag distribution of normal stresses through the thickness) in the glass layers, we need to estimate two stresseffective thicknesses for each glass layer: one at the top and another one at the bottom of each layer. This means that the stress effective thickness is useful to estimate the maximum stresses, but four different stress effective thicknesses have to be calculated to determine the complete stress distribution.

As for the dynamic effective thickness for estimating the modal parameters, only one effective thickness (frequency and temperature dependent) is needed to estimate the natural frequencies and loss factors corresponding to all the modes [9]. With respect to the mode shapes, they are assumed to be equal to those of the monolithic beam with the same boundary conditions.

Due to the assumptions considered in the derivation of the effective-thickness equations $[3,4,9]$ they cannot provide exact results. However, the numerical simulations and the experimental results demonstrate that quite accurate results can be reached with this technique $[3,4,9]$.

\subsubsection{Static deflection effective thickness and deflection effective Young modulus}

The deflection effective thickness for laminated-glass beams can be determined by identifying the stiffness of a monolithic beam with Young modulus $E_{i}$ and thickness $H_{e f f}$ and the stiffness given by Eqs. $(10,18)$, i.e.:

$\frac{E_{i} H_{e f f S}^{3}(t)}{12}=\mathrm{EI}(\mathrm{t})_{\mathrm{S}}$

where the subindex "effs" indicates effectives for static loading . 
On the other hand, the effective Young modulus is derived from:

$$
\frac{E_{e f f}(t) H^{3}}{12}=\mathrm{EI}(\mathrm{t})_{\mathrm{S}}
$$

Where $\mathrm{H}$ is the thickness of the monolithic beam. In order for the effective Young modulus to be close to that corresponding to the glass, the thickness $\mathrm{H}$ should be taken as:

$H=H_{1}+H_{2}+H_{3}$

The equations of the effective thickness and effective Young modulus for beams are shown in Table 1. If $E_{1}=E_{3}$, there is a unique effective thickness whereas two different effective thicknesses have to be defined if $E_{1} \neq E_{3}$-that is, the effective thickness differs depending on whether the monolithic model has Young modules $E_{1}$ or $E_{3}$. In any case, the effective Young modulus is unique.

In case of plates, three parameters are needed to define the stiffness of a plate (thickness, Young modulus and Poisson ratio). The effective thickness with Young modulus $E_{i}$ and Poisson ratio $v_{i}$ is derived from:

$\frac{E_{i} H_{e f f S}^{3}(t)}{12\left(1-v_{i}^{2}\right)}=D(\mathrm{t})_{\mathrm{S}}$

If we use a constant thickness to determine an effective Young modulus, two parameters still remain unknown: the Young modulus and the Poisson ratio. To get reasonable values for $E_{\text {eff }}$, we can take Poisson ratios equal to that corresponding to the glass, i.e. 
$\frac{E_{e f f}(t) H^{3}}{12\left(1-v_{e f f}^{2}(\mathrm{t})\right)}=D(\mathrm{t})_{\mathrm{S}}$

where $v_{e f f}(t)=v_{1}$ or $v_{e f f}(t)=v_{3}$.

The equations of the effective thickness and effective Young modulus for plates are shown in Table 1.

\subsection{Dynamic effective thickness for laminated-glass beams}

Aenlle and Pelayo [9] demonstrated that the RKU model can be considered a particular case of M\&M model when $k_{R}=0$, i.e., Eq. (31) and Eq. (35) provide the same modal parameters when $k_{R}=0$. On the other hand, the RKU model provides reasonably accurate results when $k_{R}$ is small. Thus, the effective stiffness given by Eq. (33) can be used together with the Eq. (35) to predict accurately the modal parameters of laminatedglass beams when $k_{R}$ is small. Moreover, a dynamic effective stiffness was derived from Eq. (33), which is given by:

$E I^{*}(\omega)=E I_{T}\left(1+\frac{Y}{1+\frac{E_{1} H_{1}}{g_{R}^{*}(\omega)\left(E_{1} H_{1}+E_{3} H_{3}\right)}}\right)$

which can also be expressed as:

$E I^{*}(\omega)=E I_{T}\left(1+\frac{Y}{1+\frac{E_{1} H_{1} E_{3} H_{3} k_{I}^{2}}{G_{2}^{*}(\omega)\left(E_{1} H_{1}+E_{3} H_{3}\right)}}\right)$ 
The dynamic effective thickness and the effective Young modulus are estimated using the same methodology as that used in statics, and the results are shown in Table 2.

Using the same format as the effective stiffness for statics proposed by Galuppi et al., Eq. (46) can be expressed as:

$$
E I^{*}(\omega)=\frac{1}{\frac{\eta_{\mathrm{d}}(\omega)}{\mathrm{EI}_{\mathrm{T}}(1+\mathrm{Y})}+\frac{1-\eta_{d}(\omega)}{\mathrm{EI}_{\mathrm{T}}}}
$$

where

$$
\begin{array}{r}
\eta_{d}(\omega)=\frac{1}{1+\frac{E_{1} H_{1}}{g_{R}^{*}(\omega)\left(E_{1} H_{1}+E_{3} H_{3}\right)(1+Y)}} \\
=\frac{1}{1+\frac{E_{1} H_{1} H_{2} E_{3} H_{3} k_{I}{ }^{2}}{G_{2}^{*}(\omega)\left(E_{1} H_{1}+E_{3} H_{3}\right)(1+Y)}}
\end{array}
$$

\section{A MODEL FOR THE DYNAMIC BEHAVIOUR OF LAMINATED-GLASS PLATES}

In this section, we extend the model of Ross, Kerwin and Ungar to rectangular laminated-glass plates. Furthermore, a dynamic effective thickness and a dynamic effective Young modulus are derived to estimate the modal parameters in laminatedglass plates. The method is based on the relationship that exists between the static $E I(t)_{S}$ and the dynamic $E I^{*}(t)$ stiffness in beams.

3.1 Relation between $\mathrm{EI}(\mathrm{t})_{\mathrm{S}}$ and $E I^{*}(\omega)$ in beams. 
From Eqs. (18) and (48) it is inferred that the only difference between them (apart from the time $t$ and the frequency $\omega$ ) are the parameters $\psi_{B}$ and $k_{I}$.

In Galuppi and Royer Carfagni [3], it is proposed to calculate the parameter $\psi_{B}$ (Eq. (17) ) by means of:

$\psi_{B}=\frac{\int_{-\mathrm{L} / 2}^{L / 2} g^{\prime \prime}(x)^{2} d x}{\int_{-\mathrm{L} / 2}^{L / 2} g^{\prime}(x)^{2} d x} ; \quad-\frac{\mathrm{L}}{2} \leq \mathrm{x} \leq \mathrm{L} / 2$

Where $\mathrm{g}(x)$ is a function equal in shape to the bending deflection of an elastic monolithic beam with constant cross-section under the same loading and boundary conditions as the problem at hand.

On the other hand, the critical load of an elastic monolithic beam with constant crosssection and stiffness $E I$, using the Rayleigh Ritz method with an approximate deflection curve $\mathrm{g}(x)$, is given by:

$N_{c r i t}=\frac{\pi^{2} E I}{\left(L_{e f f}\right)^{2}}=\frac{\int_{-\mathrm{L} / 2}^{L / 2} E I g^{\prime \prime}(x)^{2} d x}{\int_{-\mathrm{L} / 2}^{L / 2} g^{\prime}(x)^{2} d x}$

where $L_{e f f}$ is the effective length. Identifying Eqs. (50 and (51) we get:

$L_{e f f}=\frac{\pi}{\sqrt{\psi_{B}}}$

This means that the parameter $\psi_{B}$ is related to the effective length $L_{e f f}=\beta L, \beta$ being the buckling ratio of the beam, i.e. with the semi-wavelength of the deflection curve (distance between the inflection points). The result of Eq. (52) can be checked with the values of $\psi_{B}$ provided in Table 1 of [37].

On the other hand, the wavenumber $k_{I}$ is related to the wavelength $\lambda$ by means of: 
Thus, the wavenumber $k_{I}$ plays in dynamics the same role as parameter $\sqrt{ } \psi_{B}$ in statics or, alternatively, the effective length $L_{e f f}$ (semi-wavelength of the deflection curve) plays the same role in statics as the semi-wavelength $\frac{\lambda}{2}$ in dynamics. This also means that the dynamic stiffness can be determined from the static stiffness changing time $(\mathrm{t})$ per frequency $(\omega)$ and $\sqrt{ } \psi_{B}$ per $k_{I}$.

Therefore, $\mathrm{EI}(\mathrm{t})_{\mathrm{S}}$ depends on the boundary conditions and its effect can be described with the parameter $\psi_{B}$ or, alternatively, with the effective length of the buckling-mode shape. With respect to $E I^{*}(\omega)$, the effect of the boundary conditions is considered with the wavenumber $k_{I}$. For a simply supported beam, the parameters $\psi_{B}$ and $k_{I}$ are given by:

$\psi_{B}=k_{I}^{2}=\frac{n^{2} \pi}{L^{2}}$

where $\mathrm{n}$ is an integer indicating the order of the mode. The relation given by Eq. (52) is expected because in the models developed in [3] and [9] it is assumed that the static and the dynamic deflection shapes of laminated-glass beams are equal to those of the monolithic beams.

32. Extension to rectangular plates.

In this section, the relation between the static and the dynamic stiffness derived for beams can are extended to rectangular plates. In [4] the parameter $\psi_{P}$ for plates, is given by:

$$
\psi_{P}=\frac{\int_{\Omega}\left[\left(\frac{\partial^{2} g(x, y)}{\partial x^{2}}+\frac{\partial^{2} g(x, y)}{\partial y^{2}}\right)^{2}-2(1-v)\left(\frac{\partial^{2} g(x, y)}{\partial x^{2}} \frac{\partial^{2} g(x, y)}{\partial y^{2}}-\left(\frac{\partial^{2} g(x, y)}{\partial x \partial y}\right)^{2}\right)\right] d x d y}{\int_{\Omega}\left[\left(\frac{\partial g(x, y)}{\partial x}\right)^{2}+\left(\frac{\partial g(x, y)}{\partial y}\right)^{2}\right] d x d y}
$$


Where $\Omega$ is the domain of the plate and $g(x, y)$ is a function equal in shape to the bending deflection of an elastic monolithic plate with constant cross-section under the same loading and boundary conditions of the problem at hand.

On the other hand, the critical loading of a rectangular plate subject to normal loadings $N_{x}=N, N_{y}=N$ and $N_{x y}=0$ using the Rayleigh-Ritz method with an approximate deflection surface $g(x, y)$ is given by:

$$
N_{\text {crit }}=D \frac{\int_{\Omega}\left[\left(\frac{\partial^{2} g(x, y)}{\partial x^{2}}+\frac{\partial^{2} g(x, y)}{\partial y^{2}}\right)^{2}-2(1-v)\left(\frac{\partial^{2} g(x, y)}{\partial x^{2}} \frac{\partial^{2} g(x, y)}{\partial y^{2}}-\left(\frac{\partial^{2} g(x, y)}{\partial x \partial y}\right)^{2}\right)\right] d x d y}{\int_{\Omega}\left[\left(\frac{\partial g(x, y)}{\partial x}\right)^{2}+\left(\frac{\partial g(x, y)}{\partial y}\right)^{2}\right] d x d y}
$$

Identifying Eqs. (55) and (56), the critical load is given by:

$$
N_{c r i t}=D \psi_{P}
$$

For the particular case of a simply supported plate:

$N_{c r i t}=D \pi^{2}\left(\left(\frac{m}{a}\right)^{2}+\left(\frac{n}{b}\right)^{2}\right)$

Where $m$ and $n$ are the half-waves of buckling in $\mathrm{x}$ and $\mathrm{y}$ directions, respectively, and $a$ and $b$ are the dimensions of the plate in the same directions.

From Eqs. (57) and (58) it is derived that for this particular boundary condition:

$$
\psi_{P}=\pi^{2}\left(\left(\frac{m}{a}\right)^{2}+\left(\frac{n}{b}\right)^{2}\right)
$$

With respect to the wavenumbers of a simply supported plate, they are given by: 
$k_{I}^{2}=\pi^{2}\left(\left(\frac{m}{a}\right)^{2}+\left(\frac{n}{b}\right)^{2}\right)$

i.e. $\psi_{P}=k_{I}^{2}$, as in monolithic plates.

Thus, the parameter $\psi_{P}$ is related, as in beams, to the dimension of the half-waves that the plates buckle into, i.e. the stiffness $D(t)_{S}$ depends on the boundary conditions. A dynamic stiffness $D^{*}(\omega)$ can be derived from the static stiffness $D(t)_{S}$ (Eq. (21)) of the Galuppi and Royer Carfagni model by extending to plates the relationship between the static and the dynamic stiffnesses derived for beams, i.e. changing time (t) per frequency $(\omega)$ and $\psi_{P}$ per $k_{I}^{2}$. With this assumption, the dynamic stiffness $D^{*}(\omega)$ is expressed as:

$$
D^{*}(\omega)=\frac{1}{\left(\frac{\eta_{d P}(\omega, T)}{\left(D_{1}+D_{3}\right)\left(1+Y_{P}\right)}+\frac{1-\eta_{d p}(\omega)}{D_{1}+D_{3}}\right)}
$$

where the parameter $\eta_{d P}(\omega)$ is given by:

$$
\eta_{d p}(\omega)=\frac{1}{1+\frac{\left(D_{1}+D_{3}\right) H_{2}}{G_{2}^{*}(\omega) D_{t o t}} \frac{12 D_{1} D_{3}}{\left(D_{1} H_{3}^{2}+D_{3} H_{1}^{2}\right)} k_{I}^{2}}
$$

or alternatively

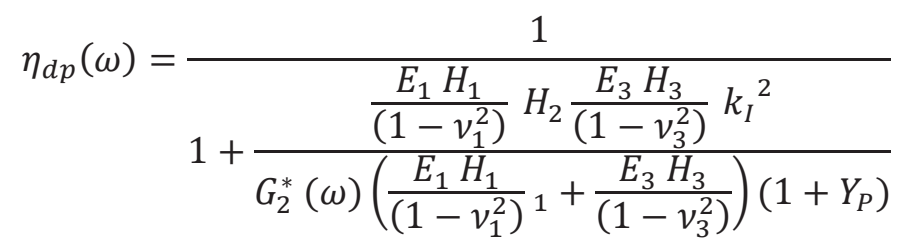

The stiffness given by Eq. (61) can be considered an effective stiffness for laminatedglass plates - that is, a monolithic plate model with stiffness $D^{*}(\omega)$ will give the same 
modal parameters as the laminated-glass plate. Finally, the natural frequencies and loss factors are found by means of:

$\omega^{2}(1+i \eta)=\mathrm{k}_{\mathrm{I}}^{4} \frac{D^{*}(\omega)}{(\rho H)_{e q}}$

With respect to the mode shapes, it has been validated by experimental tests in laminated-glass elements [41] and finite element models [42, 43] that the mode shapes of laminated-glass beams and plates present a very good correlation with those corresponding to a monolithic element with the same dimensions and supports as the laminated-glass element. This assumption has also been considered in this paper.

\subsection{Dynamic effective thickness for laminated-glass plates}

The dynamic effective thickness with Young modulus $E_{i}$ and Poisson ratio $v_{i}$ is derived from:

$$
\frac{E_{i} H_{i e f f}(\omega)^{3}}{12\left(1-v_{i}^{2}\right)}=D^{*}(\omega)
$$

From Eqs. (61) and (65) it is inferred that the dynamic effective thicknesses are given by:

$$
H_{1 e f f}(\omega)=\sqrt[3]{\frac{12\left(D_{1}+D_{3}\right)\left(1+Y_{P}\right)}{E_{1}\left(1-v_{1}^{2}\right)\left(1+Y_{P}\left(1-\eta_{d p}(\omega)\right)\right)}}
$$

and

$$
H_{3 e f f}(\omega)=\sqrt[3]{\frac{12\left(D_{1}+D_{3}\right)\left(1+Y_{P}\right)}{E_{3}\left(1-v_{3}^{2}\right)\left(1+Y_{P}\left(1-\eta_{d p}(\omega)\right)\right)}}
$$


whereas the effective Young modulus is expressed as:

$E_{e f f}(\omega)=\frac{12\left(1-v_{e f f}^{2}\right)\left(D_{1}+D_{3}\right)\left(1+Y_{P}\right)}{H^{3}\left(1+Y_{P}\left(1-\eta_{d P}(\omega)\right)\right)}$

where $v_{e f f}=v_{1}$ or $v_{e f f}=v_{1}$. If $E_{1}=E_{3}$ and $v_{1}=v_{3}$ Eq. (63) simplifies to:

$$
\eta_{d p}(\omega)=\frac{1}{1+\frac{E_{1} H_{1} H_{2} H_{3} k_{I}^{2}}{G_{2}^{*}(\omega)\left(H_{1}+H_{3}\right)(1+Y)\left(1-v_{1}^{2}\right)}}
$$

Eqs. (66) and (67) to:

$H_{1 e f f}(\omega)=H_{3 e f f}(\omega)=\sqrt[3]{\frac{\left(H_{1}^{3}+H_{3}^{3}\right)(1+Y)}{1+Y\left(1-\eta_{d p}(\omega)\right)}}$

and Eq. (68) to:

$$
E_{e f f}(\omega)=\frac{\left(H_{1}^{3}+H_{3}^{3}\right)(1+Y)}{H^{3}\left(1+Y\left(1-\eta_{d P}(\omega)\right)\right)}
$$




\section{4 METHODOLOGY}

\subsubsection{Methodology I. Stiffness Method}

This methodology is recommended when the wavenumbers $\mathrm{k}_{\mathrm{I}}$ are known from the literature (see e.g. [39]) and it is shown schematically in Fig 3. The technique consists of the following steps:

1. To estimate an initial natural frequency $\omega_{0}$. The laminated-glass plates have two border lines [2] (the layered limit and the monolithic limit) so that the natural frequency has to be within the range:

$\mathrm{k}_{\mathrm{I}}^{4} \frac{D_{\text {layered }}}{(\rho H)_{\text {eq }}} \leq \omega_{0} \leq k_{I}^{4} \frac{D_{\text {monolithic }}}{(\rho H)_{e q}}$

The average of both limits can be taken as the initial natural frequency, so that:

$$
\begin{aligned}
\omega_{0}^{2}=\frac{\frac{\mathrm{k}_{\mathrm{I}}^{4}}{(\rho H)_{e q}}\left(D_{\text {monolithic }}+D_{\text {layered }}\right)}{2} & \\
= & \frac{\mathrm{k}_{\mathrm{I}}^{4} D_{\text {monolithic }}}{(\rho H)_{e q}}\left(1+\frac{H_{1}^{3}+H_{3}^{3}}{\left(H_{1}+H_{2}+H_{3}\right)^{3}}\right)
\end{aligned}
$$

2. To calculate $\eta_{d p}(\omega)$ with Eq. (63). The wavenumbers corresponding to each mode are needed in Eq. (63) and those corresponding to a monolithic plate with the same boundary conditions can be used with reasonable accuracy. They can be taken from the literature [39] for the most common cases.

3. To calculate $D^{*}(\omega)$ with Eq. (61).

4. To calculate the natural frequency $\omega$ and the loss factor $\eta$ with Eq. (64).

5. To repeat steps 2,3 , and 4 up to convergence (the error between the frequency $\omega$ in steps 2 and 3 and the frequency $\omega$ in step 4 is small)

In these steps, $\omega=\omega_{0}$ is considered in the first iteration. 


\subsubsection{Methodology II: effective thickness}

This methodology, based on the dynamic effective thickness concept is recommended when the wavenumbers corresponding to the boundary conditions are not known from the literature. The procedure, shown schematically in Fig 4, is the following:

1. To assemble a monolithic FE model with the same dimensions as the laminatedglass plate, thickness $H=H_{1}+H_{2}+H_{3}$, material properties $E_{1}, v_{1}$ and density:

$\rho_{e q}=\frac{\rho_{1} H_{1}+\rho_{2} H_{2}+\rho_{3} H_{3}}{H_{1}+H_{2}+H_{3}}$

Alternatively, material properties $E_{3}, v_{3}$ can be used if $H_{3 e f f}$ is considered in Eq. (65).

This monolithic model will provide us the following information:

- The mode shapes of the laminated-glass plate.

- The wavenumbers $k_{I}$ needed in Eqs. (63) and (65). They can be estimated from the natural frequencies of the finite-element monolithic model using the equation:

$\omega_{\text {mon }}^{2}=k_{I}^{4} \frac{E_{1} H^{3}}{12\left(1-v_{1}^{2}\right) \rho_{e q} H}$

where the wavenumbers are the only unknowns.

- An initial natural frequency $\omega_{0}$ which can be estimated with the equation: 
$\omega_{0}^{2}=\frac{\frac{12 \mathrm{k}_{\mathrm{I}}^{4}}{\left(1-v_{1}^{2}\right)(\rho H)_{e q}}\left(\left(H_{1}+H_{2}+H_{3}\right)^{3}+\left(H_{1}^{3}+H_{3}^{3}\right)\right)}{2}$

which is the average between the layered and the monolithic limit.

2. To calculate $\eta_{d p}(\omega)$ with Eq. (63).

3. To calculate the effective thickness, $H_{1 e f f}(\omega)$ with Eq. (64).

4. To calculate the natural frequency and the loss factors with:

$\omega^{2}(1+i \eta)=\omega_{m o n}^{2} \frac{H_{1 e f f}(\omega)^{3}}{H^{3}}$

5. To repeat steps 2,3 , and 4 up to convergence (the error between the frequency $\omega$ in steps 2 and 3 and the frequency $\omega$ in step 4 is small).

Once again, in these steps, $\omega=\omega_{0}$ is considered in the first iteration. 


\section{EXPERIMENTAL TESTS}

\subsection{Laminated-glass plate}

A rectangular laminated-glass plate $1400 \times 1000 \mathrm{~mm}$ and thickness $\mathrm{H}_{1}=7.82 \mathrm{~mm}$, $\mathrm{H}_{2}=0.76 \mathrm{~mm}, \mathrm{H}_{3}=7.828 \mathrm{~mm}$, pinned supported at the four corners, were tested using operational modal analysis (OMA), with the temperature being $\mathrm{T}=20.5{ }^{\circ} \mathrm{C}$ (Fig 5). The interlayer was made of PVB whereas the faces were made of annealed glass. To study the effect of the supports on the damping, we made the experimental tests using two different supports. The first test was performed using four wooden balls $50 \mathrm{~mm}$ in diameter whereas four smaller steel balls $(8 \mathrm{~mm}$ in diameter) were used in the second test (see Fig. 6).

Operational Modal Analysis is a technique that allows us to estimate the model parameters (natural frequencies, mode shapes, and damping ratios) without knowing and/or controlling the input excitation [44]. OMA is a Multiple Input Multiple Output (MIMO) technique; that is, the technique is able to estimate closely space modes and even repeated modes with a high degree of accuracy. The testing is easier than the traditional modal analysis because there is no need for an exciter (vibration shaker, impact hammer, etc.). The ideal force for operational modal analysis is stationary white noise. In practice, we need only to make sure that the loading is reasonably random in time and space. The excitation produced in this way will be a good approximation of a multivariate white-noise stochastic process. Other important features are that the estimated modes are based on true boundary conditions and the actual ambient excitation sources. When operational modal analysis is applied to structures located in the labs or places where the magnitude of the natural loads is relatively low, artificial devices must be used in order to reach a reasonable load magnitude which, additionally, must be multiple-input and stationary broad banded [45]. A procedure to approximate to this loading consists of applying many hits over a large part of the structure.

The plate was excited by applying many small hits with an impact hammer on the plate surface randomly in time and space The responses of the plate were measured using 16 accelerometers with a sensitivity of $100 \mathrm{mv} / \mathrm{g}$, uniformly distributed (Figure 5). The responses were recorded for approximately 5 min with a sampling frequency of 1632 
$\mathrm{Hz}$ and using a 16 channel (4xNI9234) Compact DAQ acquisition system by National instruments. The first 8 modes were identified by OMA and the modal parameters of the plate were estimated using both the frequency-domain decomposition (FDD) [44] and the stochastic subspace iteration method (SSI) [46]. The two techniques provide similar results, and therefore only the modal parameters estimated with the FDD technique are shown in Table 3 for both types of supports.

\subsection{Laminated-glass beam}

To validate the model for different boundary conditions and also at different temperatures, we estimated the modal parameters of a free-free laminated-glass beam, with the following geometrical data: $L=1 \mathrm{~m}, H_{1}=3.75 \mathrm{~mm}, H_{2}=0.38 \mathrm{~mm}, H_{3}=$ $7.90 \mathrm{~mm}, b=0.1 \mathrm{~m}$, using OMA. The faces were also annealed glass whereas the core was PVB.

The tests were performed in a climate chamber at temperatures: $12{ }^{\circ} \mathrm{C}, 20^{\circ} \mathrm{C}, 25^{\circ} \mathrm{C}$, $30{ }^{\circ} \mathrm{C}, 35^{\circ} \mathrm{C}, 40^{\circ} \mathrm{C}$, and $45^{\circ} \mathrm{C}$. The responses of the beams were measured using 8 accelerometers with a sensitivity of $100 \mathrm{mv} / \mathrm{g}$, uniformly distributed (Figure 7) and an 8-channel National Instruments digital card. The arrows in Fig. 7 show the location and the direction of the sensors. The beam was excited by applying many hits along the beam, random in time and space, and the responses were recorded for approximately 5 min using a sampling frequency of $2132 \mathrm{~Hz}$.

The modal parameters were estimated using both frequency-domain decomposition [44] and the stochastic subspace iteration method (SSI) [46]. The modal parameters corresponding to the first three modes, estimated with the FDD technique, are presented in Table 4.

\section{VALIDATION OF THE MODEL}

\subsection{Laminated-glass plate}

The modal parameters of the plate described in the former section were also predicted using the dynamic effective concept. A Young modulus $E_{1}=72000 \mathrm{MPa}$, Poisson 
ratio $v_{1}=0.22$ and density $\rho_{1}=2500 \mathrm{~kg} / \mathrm{m}^{3}$ were considered for the glass [9]. With regard to the core of the beam, made of polyvinyl butyral (PVB), a density $\rho_{2}=$ $1030 \mathrm{~kg} / \mathrm{m}^{3}$ and the complex shear modulus $G_{2}^{*}(\omega)$ indicated in Figure 2 were considered [9].

In Section 3 two different methodologies were proposed to estimate the modal parameters of laminated-glass plate, both providing the same results. In this paper, methodology II, which considers the dynamic effective thickness concept, was used (Eqs. (66) and (77)).

A FEM of a rectangular monolithic glass plate $1400 \times 1000 \mathrm{~mm}^{2}$, thickness $H=H_{1}+$ $H_{2}+H_{3}=16.40 \mathrm{~mm}$, pin supported at the corners and material properties corresponding to the glass $\left(E_{1}, \rho_{1}, v_{1}\right)$, was assembled in ABAQUS and the natural frequencies $\omega_{F E M}$ of the first 8 modes were extracted. The wavenumbers corresponding to this monolithic model were calculated from the equation:

$\omega_{F E M}^{2}=k_{I}^{4} \frac{E_{1} \frac{\left(H_{1}+H_{2}+H_{3}\right)^{3}}{12}}{\left(1-v_{1}^{2}\right) \rho_{1}\left(H_{1}+H_{2}+H_{3}\right)}$

where the only unknowns are the wavenumbers $k_{I}$. The estimated wavenumbers, which are needed in Eqs. (66) and (77), are presented in Table 5.

Finally, following the iterative process shown in Section 3.4.2, the effective thickness, the natural frequencies and the loss factors corresponding to the first 8 modes were estimated with Eqs. (66) and (77), respectively. The effective thickness for each mode, which is complex, is shown in Table 6, whereas the natural frequencies and loss factors are presented in Table 5. It has been considered that loss factor and the modal damping ratio $\zeta$ are related by [47]:

$\eta=2 \cdot \zeta$ 
It can be seen that the natural frequencies can be estimated with an error of less than $8 \%$ for all the modes considered in the investigation. Moreover, the type of supports does not significantly affect the experimental natural frequencies of the plate.

With respect to the experimental loss factors (Table 3), the discrepancies between the results found with wooden supports and with steel supports were less than $12 \%$. On the other hand, larger discrepancies were found between the experimental and the predicted loss factors (Table 5).

The estimation of damping in structural systems is the most complex problem in structural dynamics. Unlike the mass and stiffness characteristics of a structural systems, damping does not relate to a single physical phenomenon and there are as many damping mechanisms as there are modes converting mechanical energy into heat [48]. In laminated-glass elements, the material damping contribution comes mainly from the interlayer and the contribution of glass to damping is usually neglected in the analytical models [18-24]. However, this contribution also depends on the material used for the interlayer. In case of PVB, the contribution of the glass to damping over $20^{\circ} \mathrm{C}$ can be neglected, but its effect should be taken into account under this temperature.

The mechanical characterization of the interlayer is a key step in making good damping predictions in laminated-glass elements. Although major efforts have been made in the last years in order to improve the analytical modeling of viscoelastic materials, as well as the testing and the fitting of the experimental results, the material properties are not estimated with reasonable accuracy to allow a good estimation of the damping in laminated-glass elements. In fact, the material properties proposed by several authors [50] are clearly different and lead to widely discrepant results. On other occasions, the material properties are good for static loadings but not for dynamic loadings. Another damping contribution is the interfacial damping mechanism, i.e. the friction between members, connections, and supports of a structural system. Aerodynamic damping is also experienced by a structure vibrating in air [48]. Moreover, the proposed model for plates has been extended from a model for beams. All these facts explain why the uncertainty in the loss factors is so high. However, as mentioned in this paper, this is not exclusive of laminated glass but also of other materials and structural systems. 
Table 5 shows that the predicted damping augments with increasing frequency as is the case in beams. However, this is not true of the tested plate where the modes 2, 3, 5, 7 , and 8 (bending + torsion) follow a different trend from that of modes 1, 4, and 6 (bending in one or two directions). Modes 2, 3, 5, 7, and 8 present errors less than 50\%, which is of the same order of error reported by the authors in previous tests performed on laminated-glass beams [9]. For modes 1,4 , and 6 , the error is significantly larger.

Regarding the mode shapes, the modal assurance criterion (MAC) [49] between the experimental mode shapes and those corresponding to the monolithic elastic FEM model, are shown in Table 7. It can be concluded that the experimental mode shapes of the laminated-glass plate agree well with those of the FEM monolithic model - that is, the mode shapes of laminated-glass plate are very similar to those of a monolithic plate with the same dimensions and supports as those of the laminated-glass plate.

Table 8 presents the predictions with Eq. (38) and Eq. (77). Both equations provide similar natural frequencies (differences less that $0.2 \%$ ) and the maximum discrepancies in the loss factors are around $5 \%$.

\subsection{Laminated-glass beam}

The modal parameters of the laminated-glass beam were also predicted using Eq. (35). The same material properties as those described for the plates were considered for the beam.

As in the laminated-glass plate, the modal parameters of the laminated-glass beam were estimated using the dynamic-effective-thickness concept. The initial natural frequencies for the beam were estimated from the equation:

$\omega_{0}^{2}=\frac{k_{I}^{4} E\left(\frac{H_{1}^{3}+H_{3}^{3}+\left(H_{1}+H_{2}+H_{3}\right)^{3}}{24}\right)}{\bar{m}}$

Where the wavenumbers $\mathrm{k}_{\mathrm{I}}$ are those of an Euler Bernoulli beam, which can be easily found in the literature [27]. 
Then, the effective thickness, the natural frequencies, and the loss factors were estimated following the iterative process indicated in section 3.4, but estimating $H_{\text {eff }}(\omega)$ with the expression presented in Table 2. The predictions for the first three modes in the temperature range $12-45^{\circ} \mathrm{C}$ is shown in Table 4 . Very good agreement exists for the natural frequencies at all the temperatures, the discrepancies being less than $7 \%$. It can be seen that the natural frequencies decrease as temperature increases and this tendency is expected because the modulus of the PVB declines with rising temperatures (Figure 2). Moreover, at temperatures below $20^{\circ} \mathrm{C}$, the wavenumber is close to that corresponding to an Euler-Bernoulli beam, and Eq. (35) can be used to accurately predict the natural frequencies on a laminated-glass beam at these temperatures [9].

With respect to the loss factor, large discrepancies were encountered between the results provided by the analytical model and the experimental results, the error being less than $50 \%$. From Table 4, it is inferred that the maximum loss factors are reached in the range $40-50{ }^{\circ} \mathrm{C}$, whereas damping is very small at low temperatures.

Regarding the mode shapes, again a very good correlation exists between the mode shapes of the laminated-glass beam and those corresponding to a monolithic beam, the MAC being very close to one for all the modes and all temperatures (Figure 8). Thus, we can conclude that the effect of temperature in the mode shapes of a laminated-glass beam element can be neglected.

\section{CONCLUSIONS}

In the practical calculations of laminated-glass elements, as well as in preliminary designs, it is very useful to consider simplified methods. In recent years, several equations have been proposed to calculate displacements, internal forces, stresses, etc., in laminated-glass beams and plates under static loading using the effective-thickness concept $[1,3,4,8]$. With this method, engineers can avoid the use of complex finiteelement models with small $3 \mathrm{D}$ elements which are exceedingly time consuming. The effective thickness can also be used to check the results found with numerical models. If 
the core is viscoelastic, the static effective thickness is time and temperature dependent. It has been demonstrated that this technique provides reasonably accurate results in beams and rectangular plates under common loadings and boundary conditions [3, 4, 37].

Aenlle and Pelayo [9] derived an effective thickness for the dynamic behavior of laminated-glass beams based on the model of Ross, Ungar, and Kerwin [18, 19]. The natural frequencies and the loss factors for laminated-glass beams are estimated using Eq. (35) whereas the mode shapes are considered equal to those of the monolithic beam with the same boundary conditions. The dynamic effective thickness is frequency and temperature dependent and an iterative process has to be followed to estimate the modal parameters. However, convergence is achieved in less than four iterations.

The conclusions of the paper are:

1. A dynamic effective thickness is proposed for rectangular laminated-glass plates based on the relationship between the static and the dynamic stiffness derived by the authors [9] for laminated-glass beams. Only one dynamic effective thickness (frequency and temperature dependent) is needed to estimate the natural frequencies and the loss factors of rectangular laminated-glass plates. With respect to the mode shapes, it is inferred from the experiments and the analytical models that they can be considered (without significant loss of accuracy), equal to those of the corresponding monolithic model (same dimensions and boundary conditions)

2. In monolithic beams, the buckling length, and the wavelength of the mode shapes depend on the bending stiffness $E I$, which is constant in statics and dynamics. In laminated-glass beams, the static and dynamic effective stiffnesses (Eqs. (10) and (39)) are given by different expressions but the only difference (apart from time and frequency) are the parameters $\psi_{B}$ and $k_{I}$. The same conclusion applies to static and the dynamic effective thicknesses.

It has been demonstrated that the parameter $\psi_{B}$ is related to the buckling length of beam under constant compression (Eq. (52)), whereas $k_{I}$ is related to the wavelength $\lambda$ of the mode shapes. This means that, in the same way as in monolithic beams, the buckling length (buckling wavelength) is related to the 
static effective stiffness and the wavelength of the mode shapes to the dynamic effective stiffness, respectively, with the important difference that the stiffness is time (or frequency) and temperature dependent in laminated-glass and constant in the monolithic case.

3. In rectangular monolithic plates, the wavelength of the mode shapes and the dimension of the buckling wavelength, are also related to the stiffness $D$.

It has been also demonstrated that, in the same way as the laminated-glass beams, the parameter $\psi_{P}$ for laminated-glass plates is related to the dimension of the waves that a plate buckles into when it is subject to constant compressive loading on all the borders.

The relationship that exists in laminated-glass beams between the static parameter $\psi_{B}$ and the wavenumber $k_{I}$, is extended to the two-dimensional case of rectangular glass plates but considering the parameters $\psi_{P}$ and the wavenumbers $k_{I}$ corresponding to plates.

4. The concept of effective Young modulus is proposed as an alternative to effective thickness, which can also be derived from the effective stiffness. The effective Young modulus is more appealing for use in numerical and analytical models because the monolithic model has constant thickness whereas a time- (or frequency-) and temperature-dependent Young modulus is defined.

5. In order to validate the methodology, the modal parameters of a laminated-glass plate $1400 \times 1000 \times 16 \mathrm{~mm}$, with annealed glass and PVB core, pin supported at the four corners, were estimated using the dynamic effective thickness. The wavenumbers needed in Eq. (62) were estimated from a monolithic finiteelement model assembled in ABAQUS. The natural frequencies and the loss factors were estimated with Eq. (77) whereas the mode shapes were considered equal to those of the monolithic model.

The analytical predictions were validated by operational modal analysis and the experimental results show that good accuracy is attained in the natural frequencies (error less than 7\%) but high scatter is achieved in the loss factors. However, it is not possible to discriminate whether this large error in the loss factors is due to inaccuracies of the model or to a poor mechanical 
characterization of the core material (PVB). Furthermore, it has inferred from the experiments that the type of supports used in tests do not significantly affect the damping.

With respect to the mode shapes, the modal assurance criteria (MAC) between the predicted and the experimental mode shapes are very close to unity for all the modes, indicating a very good correlation.

6. With the purpose of validating the model for different temperatures and boundary conditions, the modal parameters of a free-free laminated-glass beam in the temperature range from 12 to $45^{\circ} \mathrm{C}$ and with the geometrical data $L=$ $1 \mathrm{~m}, H_{1}=3.75 \mathrm{~mm}, H_{2}=0.38 \mathrm{~mm}, H_{3}=7.90 \mathrm{~mm}, b=0.1 \mathrm{~m}$, were estimated using the effective-thickness concept. The results were validated by operational modal tests conducted in a climate chamber at temperatures from 12 to $45^{\circ} \mathrm{C}$. Good accuracy was achieved in the natural frequencies (error less than $7 \%$ ) whereas the maximum error in the loss factors was around $50 \%$. With respect to the mode shapes, again the MAC is very close to unity for all the modes at all the temperatures, which means that the mode shapes are not affected significantly by temperature.

\section{ACKNOWLEDGMENTS}

The economic support given by the Spanish Ministry of Education through the project BIA2011-28380-C02-01 is gratefully appreciated. 


\section{REFERENCES}

[1] Benninson, S., M.HX, Q. and Davies, P., High-performance laminated glass for structurally efficient glazing. Innovative Light-weight Structures and Sustainable Facades, Hong Kong, May, 2008.

[2] Norville, H.S., King, K.W., and Swoord, J.L., Behavior and strength of laminated glass," J Eng Mech. 1998;124(1):46-53.

[3] Galuppi, L., and Royer-Carfagni, G.F., Effective Thickness of Laminated Glass Beams: New Expression via a Variational Approach, J Struct Eng, 2012;38:53-67.

[4] Galuppi, L., and Royer-Carfagni, G.F., The Effective Thickness of Laminated Glass Plates, J Mech Mater Struct ures, 2012;7(4):375-400.

[5] Ivanov, I.V., Analysis, Modeling and Optimization of Laminated Glasses as Plane Beam, Int J Solids Struct, 2006;43(22-23):6887-6907.

[6] Koutsawa, Y., and Daya, E.M., Static and Free Vibration Analysis of Laminated Glass Beam on Viscoelastic Supports, Int J Solids Struct, 2007;44:8735-8750.

[7] Asik, M.Z., Tezcan, S., A Mathematical Model for the Behavior of Laminated Glass Beams, Comput Struct. 2005;83:1742-1753.

[8] Calderone, I., Davies, P.S., and Benninson, S.J., Effective Laminate Thickness for the Design of Laminated Glass. In: Glass Processing Days, Tampere, Finland, 2009.

[9] López-Aenlle, M., Pelayo, F., Frequency Response of Laminated Glass Elements: Analytical Modelling and Effective Thickness, Appl Mech Rev, 2013;65(2), 020802 (13 pages).

[10] Foraboschi P., Analytical Solution of two layer beam taking into account nonlinear interlayer slip. ASCE J. Eng. Mech., 2009, 135(10), 1129-1146.

[11] Benninson, S.J., Jagota, A., and Smith, C.A., Fracture of Glass/pvb Laminates in Biaxial Flexure, J Am Ceram Soc, 1999;82(7):1761-1770. 
[12] Lee, E.H., Stress Analysis in Viscoelastic Bodies, Q J Mech Appl Math, 1955;13:183-190.

[13] Read, W.T., Stress Analysis for Compressible Viscoelastic Materials. J Appl Phys, 1950;21:671-674.

[14] Ferry, J.D., Viscoelastic Properties of Polymers, Third ed., John Wiley \& Sons, Ltd., New York. 1980.

[15] Williams, M.L., Landel, R.F., and Ferry, J., The Temperature Dependence of Relaxation Mechanisms in Amorphous Polymers and Other Glass-forming Liquids, J Am Chem Soc, 1955;77:3701-3707.

[16] Tschoegl, N.W., The Phenomenological Theory of Linear Viscoelastic Behavior, Springer-Verlag, Berlin. 1989.

[17] Foraboschi, P., Analytical model for laminated-glass plate, Compos Part B-Eng, 2012;43(5):2094-2106.

[18] Kerwin, E.M., Damping of Flexural Waves by a Constrained Viscoelastic Layer, J. Acoust. Soc. Am, 1959;31(7):952-962.

[19] Ross, D., Ungar, E.E., and Kerwin, E.M., Damping of Plate Flexural Vibrations by Means of Viscoelastic Laminate, Structural Damping, ASME, 1959; p. 49-88.

[20] DiTaranto, R.A., and McGraw, Jr, J.R., Vibratory Bending of Damped Laminated Plates, J Eng Ind, 1969;91(4):1081-1090.

[21] DiTaranto, R.A., Theory of Vibratory Bending for Elastic and Viscoelastic Layered Finite-Length Beams, J Appl Mech, 1965;32:881-886.

[22] Mead, D.J., and Markus, S., The Forced Vibration of a Three-Layer, Damped Sandwich Beam with Arbitrary Boundary Conditions, J Sound Vib, 1969;10(2):163175. 
[23] Mead D.J., and Markus, S., Loss Factors and Resonant Frequencies of Encastré Damped Sandwich Beam, J Sound Vib, 1970;12(1):99-112.

[24] Rao, D.K., Frequency and Loss Factors of Sandwich Beams under Various Boundary Conditions, J Mech Eng Sci, 1978;20(5):271-282.

[25] Foraboschi, P., Behavior and Failure Strength of Laminated Glass Beams. J Eng Mech. (ASCE), 2007;133:1290-1301.

[26] Foraboschi, P., Three-layered sandwich plate: Exact mathematical model. Compos Part B-Eng, 2013;45:1601-1612

[27] Foraboschi, P., Three-layered plate: Elasticity solution. Compos Part B-Eng, in press, 2014.

[28] Foraboschi, P., Layered plate with discontinuous connection: Exact mathematical model. Compos Part B-Eng, 2013;47:365-378.

[29] Foraboschi, P., Hybrid Laminated-Glass plate: Design and assessment. Compos Struct, 2013; 106:250-263.

[30] D’Ambrisi, A., Feo, L., Focacci, F., Bond-slip relations for PBO-FRCM materials externally bonded to concrete. Compos Part B-Eng, 2012; 43(8):2938-2949.

[31] D’Ambrisi, A., Feo, L., Focacci, F., Experimental analysis on bond between PBOFRCM strengthening materials and concrete. Compos Part B-Eng, 2013; 44(1): 524532.

[32] D’Ambrisi, A., Feo, L., Focacci, F., Experimental and analytical investigation on bond between Carbon-FRCM materials and masonry. Compos Part B-Eng, 2013; 46:1520.

[33] Labuz, J.F., Biolzi, L., Characteristic strength of quasi-brittle materials. Int J Solids Struct. 1998; 35(31-32):4191-4203. 
[34] Biolzi, L., Cattaneo, S., Rosati, G., Progressive damage and fracture of laminated glass beams, Constr Build Mater, 2010; 24(4):577-584.

[35] Foraboschi, P., Laminated glass column, Int J Struct Eng, 2009;87:20-26.

[36] Wölfel, E., Nachgiebiger Verbund Eine Näherungslösung und deren Anwendungsmöglichkeiten, In: Stahlbau, 1987;6:173-180.

[37] Galuppi, L., Manara, G. and Royer-Carfagni, G., Practical expressions for the design of laminated glass. Compos Part B-Eng, 2013;45:1677-1688.

[38] Wang, C.M., Vibration Frequencies of Simply Supported Polygonal Sandwich Plates via Kirchhoff Solutions. J Sound Vib, 1996;190(2):255-260.

[39] Blevins, R.D., Formulas for natural Frequency and Mode Shapes, Krieger Publishing Company, Malabar, Florida, 2001.

[40] Nashif, A.D., Jones, D.I.G., and Henderson, J.P., Vibration Damping. John Willey and Sons, New York. 1985.

[41] Blasón, S., López-Aenlle, M., Pelayo, F., Influence of Temperature on the Modal Parameters of Laminated Glass Beams, In Proc. Of the International Conference on Vibration Problems (ICOVP13). Lisbon, 2013, paper-504, p. 270.

[42] López-Aenlle, M., Pelayo, F., Villa, L.M., Barredo, J., Hermanns, L. and Fraile, A., Operational Modal Analysis on Laminated Glass Beams. In proc. Of the $4^{\text {th }}$ International Operational Modal Analysis Conference (IOMAC11). Istambul, 2011.

[43] Pelayo, F., López-Aenlle, M., Hermanns, L. and Fraile, A., Modal Scaling of a Laminated Glass Plate. In Proc. Of the $5^{\text {th }}$ International Operational Modal Analysis Conference (IOMAC), Guimaraes, 2013, paper 175. 
[44] Brincker, R., Zhang, L-M., and Andersen. P., Modal Identification from Ambient Response Using Frequency Domain Decomposition, in: Proceedings of the $18^{\text {th }}$ International Modal Analysis Conference (IMAC), San Antonio, 2000, p. 625-630.

[45] Pelayo, F., López-Aenlle, M., Brincker, R. and Fernández-Canteli, A., Artificial Excitation in Operational Modal Analysis, In Proc. Of the $3^{\text {th }}$ International Operational Modal Analysis Conference (IOMAC). Portonovo, Ancona. 2009, Paper 223.

[46] Van Overschee, P., and De Moor, B., Subspace Identification for Linear Systems: Theory, Implementation \& Applications, Dordrecht, Netherlands, Kluwer Academic Publishers. 1996.

[47] Wanbo, L., Experimental and Analytical Estimation of Damping in Beams and Plates with Damping Treatments, Ph.D. Thesis, University of Kansas, 2008.

[48] Kareem, A. and Gurley, K., Damping in structures: its evaluation and treatment of uncertainty, J Wind Eng Ind Aerod, 1996;56:131-157.

[49] Ewins, D.J., Modal testing: theory, practice and application. Second Ed. Research Studies Press, LTD. John Willey and Sons, LTD. England, 2000.

[50] Feldmann, M., Kasper, R. et al. Guidance for European Structural Desing of Glass Components. JCR Scientific and Policy Report, doi: 10.2788/5523, 2014. 


\section{FIGURE CAPTIONS:}

Figure 1: Laminated glass.

Figure 2: Tensile and shear moduli of PVB at $20^{\circ} \mathrm{C}$.

Figure 3. Estimation of natural frequencies and loss factors using methodology I.

Figure 4. Estimation of natural frequencies and loss factors using methodology II.

Figure 5. Test setup of the plate. a) Picture of the plate without sensors. b) Location of the accelerometers (arrows show accelerometers direction).

Figure 6. a) Detail of the wooden support. b) Detail of the steel support.

Figure 7. Test setup of the beam (arrows show accelerometers direction).

Figure 8. MAC between the experimental and analytical mode shapes at different temperatures. 


\section{TABLE CAPTIONS}

Table 1. Static effective thickness and effective Young modulus for laminated-glass beams and plates.

Table 2. Dynamic effective thickness and effective Young modulus for laminated-glass beams.

Table 3. Experimental modal parameters for the plate.

Table 4. Experimental and predicted natural frequencies and loss factors for the beam

Table 5. Comparison of experimental and predicted modal parameters for the plate.

Table 6. Effective thicknesses for the plate at $20.5^{\circ} \mathrm{C}$.

Table 7. Mode shapes and MAC between experimental and FE model for the plate.

Table 8. Comparison of predicted modal parameters for the plate with Eqs. (38) and (77). 


\begin{tabular}{|c|c|c|}
\hline \multicolumn{2}{|l|}{ Model } & Equation \\
\hline \multirow{5}{*}{$\begin{array}{l}\text { Benninson } \\
\text { et al. } \\
\text { (beams) }\end{array}$} & \multirow[t]{2}{*}{$E_{1}=E_{3}$} & $H_{e f f}(\mathrm{t})=\sqrt[3]{\left(H_{1}^{3}+H_{3}^{3}\right)\left(1+\Gamma_{S}(t) Y_{1}\right)}$ \\
\hline & & $E_{e f f}(\mathrm{t})=\frac{E_{1}\left(H_{1}^{3}+H_{3}^{3}\right)\left(1+\Gamma_{S}(t) Y_{1}\right)}{H^{3}}$ \\
\hline & \multirow[t]{3}{*}{$E_{1} \neq E_{3}$} & $H_{1 e f f}(\mathrm{t})=\sqrt[3]{\left(H_{1}^{3}+H_{3}^{3} \frac{E_{3}}{E_{1}}\right)\left(1+\Gamma_{S}(t) Y\right)}$ \\
\hline & & 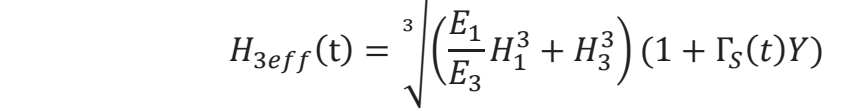 \\
\hline & & $E_{e f f}(\mathrm{t})=\frac{\left(E_{1} H_{1}^{3}+E_{3} H_{3}^{3}\right)\left(1+\Gamma_{S}(t) Y\right)}{H^{3}}$ \\
\hline \multirow{5}{*}{$\begin{array}{l}\text { Galuppi et } \\
\text { al. } \\
\text { (beams) }\end{array}$} & \multirow[t]{2}{*}{$E_{1}=E_{3}$} & $H_{e f f}(\mathrm{t})=\sqrt[3]{\frac{\left(H_{1}^{3}+H_{3}^{3}\right)\left(1+Y_{1}\right)}{1+Y_{1}\left(1-\eta_{S 1}(t)\right)}}$ \\
\hline & & $E_{e f f}(\mathrm{t})=\frac{E_{1}\left(H_{1}^{3}+H_{3}^{3}\right)\left(1+Y_{1}\right)}{H^{3} 1+Y_{1}\left(1-\eta_{S 1}(t)\right)}$ \\
\hline & \multirow[t]{3}{*}{$E_{1} \neq E_{3}$} & $H_{1 e f f}(\mathrm{t})=\sqrt[3]{\frac{12 E I_{T}(1+Y)}{E_{1}\left(1+Y\left(1-\eta_{S}(t)\right)\right)}}$ \\
\hline & & $H_{3 e f f}(\mathrm{t})=\sqrt[3]{\frac{12 E I_{T}(1+Y)}{E_{3}\left(1+Y\left(1-\eta_{S}(t)\right)\right)}}$ \\
\hline & & $E_{e f f}(\mathrm{t})=\frac{\left.12 E I_{T}(1+Y)\right)}{H^{3}\left(1+Y\left(1-\eta_{S}(t)\right)\right)}$ \\
\hline $\begin{array}{l}\text { Galuppi et } \\
\text { al. } \\
\text { (plates) }\end{array}$ & $E_{1} \neq E_{3}$ & $H_{1 e f f}(\mathrm{t})=\sqrt[3]{\frac{12\left(1-v_{1}^{2}\right)\left(D_{1}+D_{3}\right)\left(1+Y_{P}\right)}{E_{1}\left(1+Y_{P}\left(1-\eta_{S P}(t)\right)\right)}}$ \\
\hline
\end{tabular}




\begin{tabular}{|l|l|}
\hline & $E_{\text {eff }}(\mathrm{t})=\frac{12\left(1-v_{\text {eff }}^{2}\right)\left(D_{1}+D_{3}\right)\left(1+Y_{P}\right)}{H^{3}\left(1+Y_{P}\left(1-\eta_{S P}(t)\right)\right)}$ \\
\hline & \\
\hline
\end{tabular}




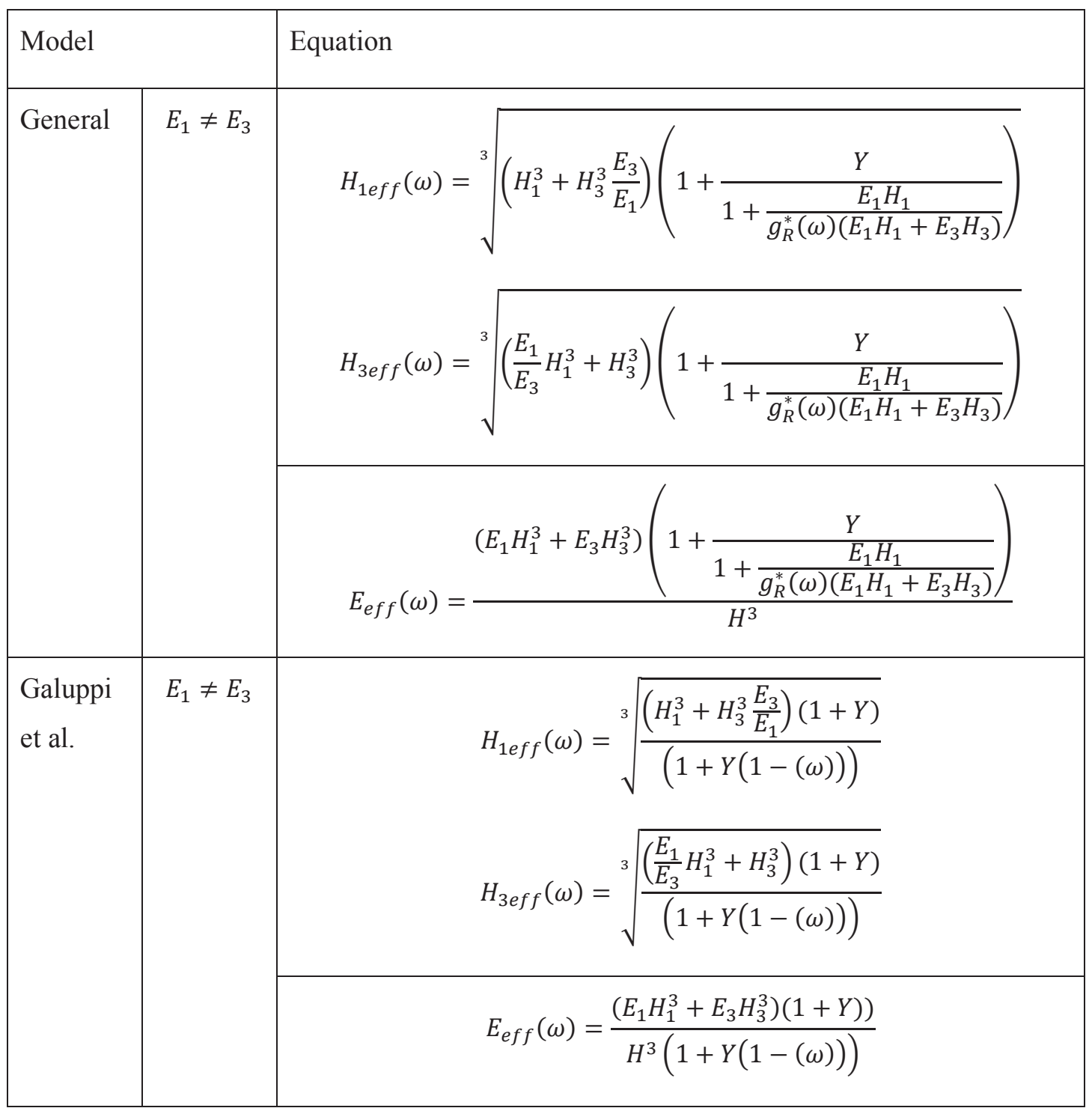




\begin{tabular}{|c|c|c|c|c|c|c|}
\hline \multirow{3}{*}{ Mode } & \multicolumn{3}{|c|}{ Natural Frequency } & \multicolumn{3}{|c|}{ Loss Factor $(\eta)$} \\
\hline & $\begin{array}{c}\text { Experimental } \\
\text { (Wooden supports) }\end{array}$ & $\begin{array}{l}\text { Experimental } \\
\text { (Steel supports) }\end{array}$ & Error & $\begin{array}{c}\text { Experimental } \\
\text { (Wooden supports) }\end{array}$ & $\begin{array}{l}\text { Experimental } \\
\text { (Steel supports) }\end{array}$ & Error \\
\hline & {$[\mathrm{Hz}]$} & {$[\mathrm{Hz}]$} & [\%] & {$[\%]$} & {$[\%]$} & {$[\%]$} \\
\hline 1 & 18.59 & 18.71 & -0.65 & 1.95 & 2.24 & -12.54 \\
\hline 2 & 42.34 & 42.61 & -0.64 & 3.54 & 3.65 & -3.11 \\
\hline 3 & 48.34 & 48.91 & -1.17 & 3.95 & 4.23 & -7.08 \\
\hline 4 & 65.4 & 66.07 & -1.01 & 1.53 & 1.57 & -2.32 \\
\hline 5 & 101.3 & 102.91 & -1.56 & 2.99 & 2.70 & 9.74 \\
\hline 6 & 121 & 120.90 & 0.08 & 1.34 & 1.27 & 5.02 \\
\hline 7 & 130 & 131.62 & -1.23 & 2.83 & 3.10 & -9.37 \\
\hline 8 & 162.9 & 167.11 & -2.52 & 3.88 & 3.93 & -1.44 \\
\hline
\end{tabular}




\begin{tabular}{|c|c|c|c|c|c|c|}
\hline \multirow{2}{*}{ Temperature } & \multicolumn{3}{|c|}{ Natural Frequencies } & \multicolumn{3}{|c|}{ Loss Factor $(\eta)$} \\
\hline & OMA & RKU & Error & OMA & RKU & Error \\
\hline$\left[{ }^{\circ} \mathrm{C}\right]$ & {$[\mathrm{Hz}]$} & {$[\mathrm{Hz}]$} & {$[\%]$} & {$[\%]$} & {$[\%]$} & {$[\%]$} \\
\hline & \multicolumn{6}{|c|}{ Mode 1} \\
\hline 12 & 66.65 & 66.16 & 0.74 & 0.28 & 0.15 & 46.43 \\
\hline 20 & 66.47 & 66.02 & 0.68 & 0.56 & 0.43 & 23.21 \\
\hline 25 & 66.29 & 65.78 & 0.77 & 0.95 & 0.9 & 5.26 \\
\hline 30 & 65.97 & 65.38 & 0.89 & 2.11 & 1.87 & 11.37 \\
\hline 35 & 65.37 & 64.86 & 0.78 & 4.56 & 4.15 & 8.99 \\
\hline 40 & 63.70 & 63.14 & 0.88 & 8.98 & 8.55 & 4.79 \\
\hline \multirow[t]{2}{*}{45} & 60.25 & 60.39 & -0.23 & 18.91 & 13.44 & 28.93 \\
\hline & \multicolumn{6}{|c|}{ Mode 2} \\
\hline 12 & 182.91 & 181.73 & 0.65 & 0.44 & 0.32 & 28.19 \\
\hline 20 & 182.03 & 180.79 & 0.68 & 0.97 & 0.73 & 25.42 \\
\hline 25 & 181.12 & 179.70 & 0.78 & 1.80 & 1.75 & 3.13 \\
\hline 30 & 179.33 & 177.90 & 0.80 & 3.75 & 3.16 & 15.87 \\
\hline 35 & 175.94 & 174.80 & 0.65 & 9.40 & 5.53 & 41.20 \\
\hline 40 & 168.16 & 169.66 & -0.89 & 22.98 & 12.14 & 47.17 \\
\hline \multirow[t]{2}{*}{45} & 153.72 & 157.9 & -2.72 & 20.34 & 18.35 & 9.78 \\
\hline & \multicolumn{6}{|c|}{ Mode 3} \\
\hline 12 & 357.10 & 354.38 & 0.76 & 0.50 & 0.51 & -2.00 \\
\hline 20 & 354.55 & 351.36 & 0.90 & 1.20 & 1.18 & 1.67 \\
\hline 25 & 351.37 & 348.72 & 0.75 & 2.63 & 2.42 & 7.98 \\
\hline 30 & 346.42 & 342.92 & 1.01 & 5.30 & 4.20 & 20.75 \\
\hline 35 & 335.54 & 333.99 & 0.46 & 11.87 & 7.61 & 35.89 \\
\hline 40 & 311.83 & 323.03 & -3.59 & 19.54 & 13.13 & 32.80 \\
\hline 45 & 276.82 & 295.70 & -6.82 & 25.06 & 21.95 & 12.41 \\
\hline
\end{tabular}




\begin{tabular}{ccccccccc}
\hline & & \multicolumn{3}{c}{ Natural Frequency } & & \multicolumn{3}{c}{ Loss Factor $(\eta)$} \\
\cline { 3 - 5 } \cline { 7 - 8 } Mode & $\begin{array}{c}\text { Wave- } \\
\text { number }\end{array}$ & Eq. (77) & $\begin{array}{c}\text { Experimental } \\
\text { (Wooden support) }\end{array}$ & Error & & Eq. (77) & $\begin{array}{c}\text { Experimental } \\
\text { (Wooden support) }\end{array}$ & Error \\
\cline { 3 - 4 } & & {$[\mathrm{Hz}]$} & {$[\mathrm{Hz}]$} & {$[\%]$} & & {$[\%]$} & {$[\%]$} & {$[\%]$} \\
\hline 1 & 2.103 & 18.32 & 18.59 & -1.44 & & 1.56 & 1.95 & 20.21 \\
2 & 3.169 & 41.24 & 42.34 & -2.65 & & 2.52 & 3.54 & 28.76 \\
3 & 3.455 & 48.91 & 48.34 & 1.17 & & 2.74 & 3.95 & 30.79 \\
4 & 3.888 & 61.71 & 65.4 & -5.97 & & 3.03 & 1.53 & -97.09 \\
5 & 5.010 & 101.33 & 101.3 & 0.04 & & 3.79 & 2.99 & -26.36 \\
6 & 5.287 & 112.49 & 121 & -7.57 & & 3.99 & 1.34 & -197.36 \\
7 & 5.683 & 129.40 & 130 & -0.46 & & 4.31 & 2.83 & -51.85 \\
8 & 6.447 & 165.03 & 162.9 & 1.29 & & 4.98 & 3.88 & -28.33 \\
\hline
\end{tabular}




\begin{tabular}{ccc}
\hline & \multicolumn{2}{c}{ Effective Thickness $[\mathrm{mm}]$} \\
\cline { 2 - 3 } Mode & Real part & Imaginary part \\
\hline 1 & 16.2300 & 0.0843 \\
2 & 16.1417 & 0.1357 \\
3 & 16.1173 & 0.1471 \\
4 & 16.0777 & 0.1626 \\
5 & 15.9580 & 0.2014 \\
6 & 15.9255 & 0.2119 \\
7 & 15.8777 & 0.2280 \\
8 & 15.7836 & 0.2619 \\
\hline
\end{tabular}


Table 6: Mode shapes and MAC between experimental and FEM model for the plate.

\begin{tabular}{|c|c|c|}
\hline Mode & Mode shape (FEM model) & MAC \\
\hline 1 & & 0.9986 \\
\hline 2 & & 0.9887 \\
\hline 3 & & 0.9860 \\
\hline 4 & & 0.9981 \\
\hline 5 & & 0.9918 \\
\hline 6 & & 0.9993 \\
\hline 7 & & 0.9947 \\
\hline
\end{tabular}




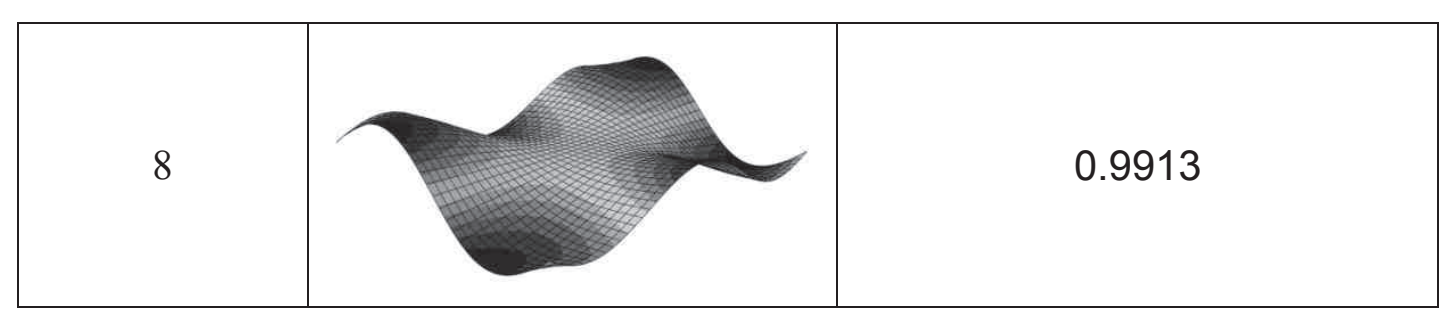




\begin{tabular}{cccccccc}
\hline \multirow{2}{*}{ Mode } & \multirow{2}{*}{$\begin{array}{c}\text { Wave- } \\
\text { number }\end{array}$} & \multicolumn{2}{c}{ Natural Frequency } & & \multicolumn{3}{c}{ Damping Ratio $(\eta)$} \\
& & $($ Eq. 38 $)$ & $($ Eq. 77) & Error & $($ Eq. 38) & (Eq. 77) & Error \\
& & {$[\mathrm{Hz}]$} & {$[\mathrm{Hz}]$} & {$[\%]$} & {$[\%]$} & {$[\%]$} & {$[\%]$} \\
\hline 1 & 2.103 & 18.33 & 18.32 & -0.05 & 1.48 & 1.56 & 4.69 \\
2 & 3.169 & 41.28 & 41.24 & -0.09 & 2.40 & 2.52 & 4.59 \\
3 & 3.455 & 48.96 & 48.91 & -0.10 & 2.61 & 2.73 & 4.57 \\
4 & 3.888 & 61.79 & 61.71 & -0.12 & 2.89 & 3.03 & 4.53 \\
5 & 5.010 & 101.51 & 101.33 & -0.17 & 3.62 & 3.78 & 4.39 \\
6 & 5.287 & 112.70 & 112.49 & -0.19 & 3.82 & 3.99 & 4.35 \\
7 & 5.683 & 129.67 & 129.40 & -0.21 & 4.12 & 4.30 & 4.28 \\
8 & 6.447 & 165.44 & 165.03 & -0.25 & 4.77 & 4.98 & 4.15 \\
\hline
\end{tabular}




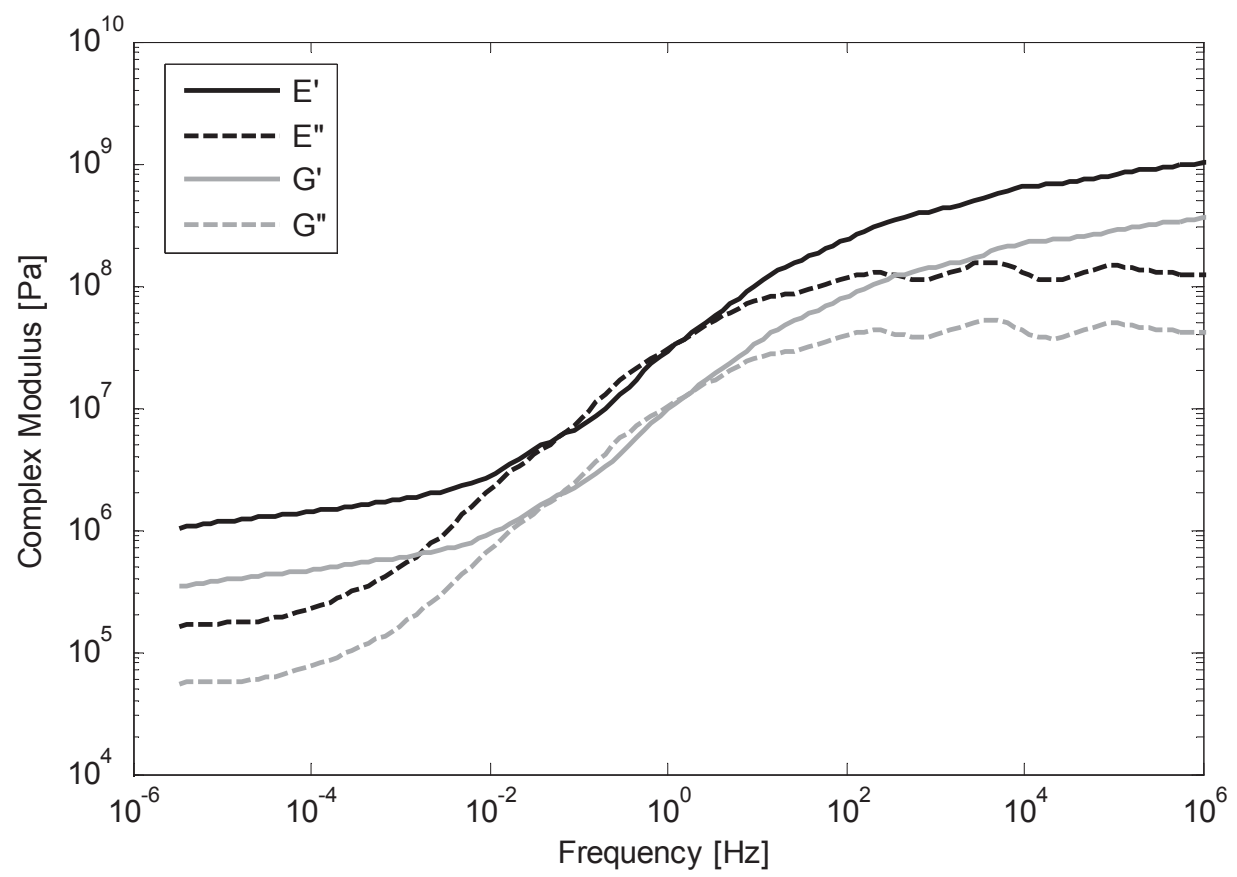




\section{Figure3}

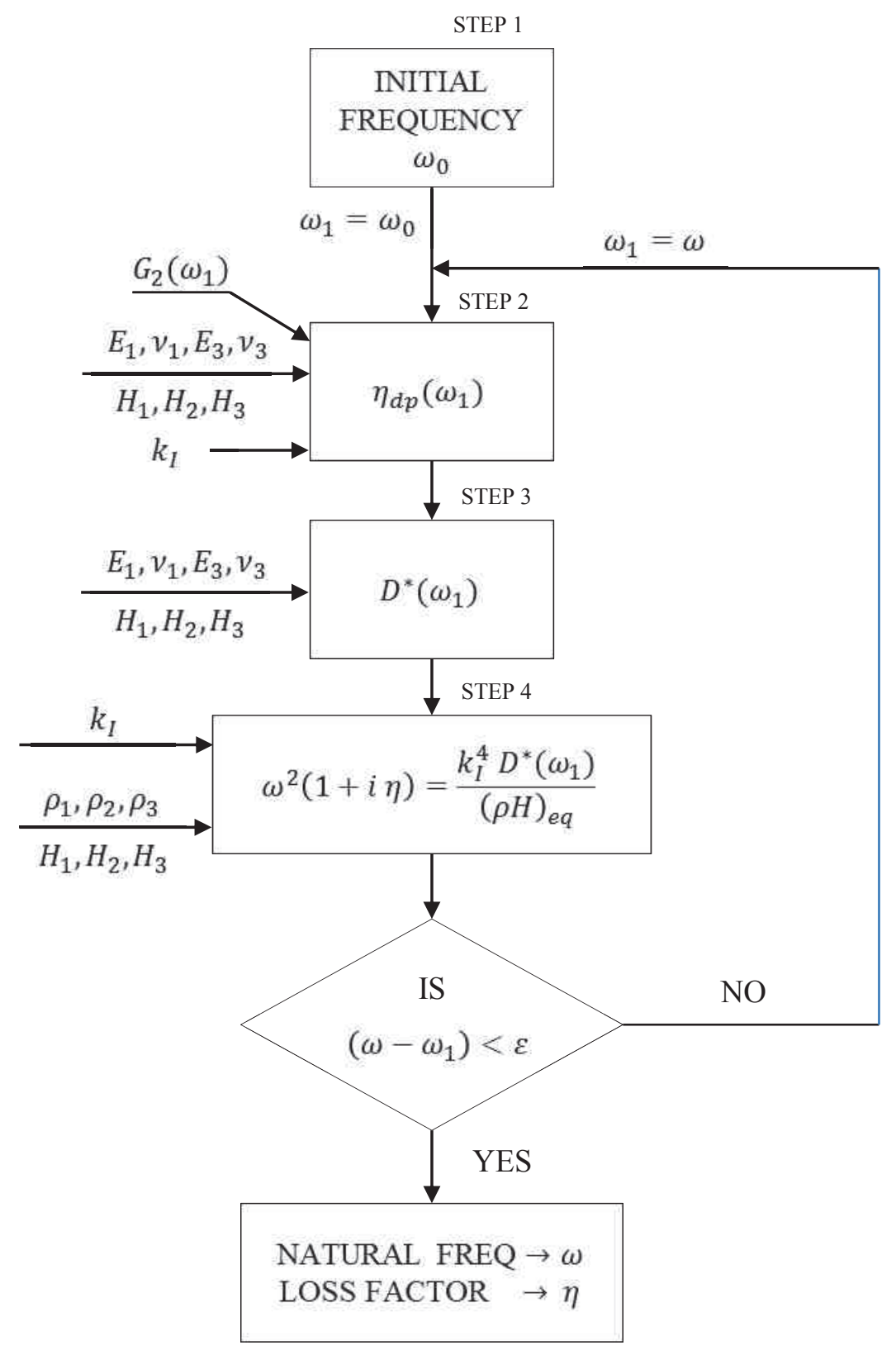




\section{Figure4}

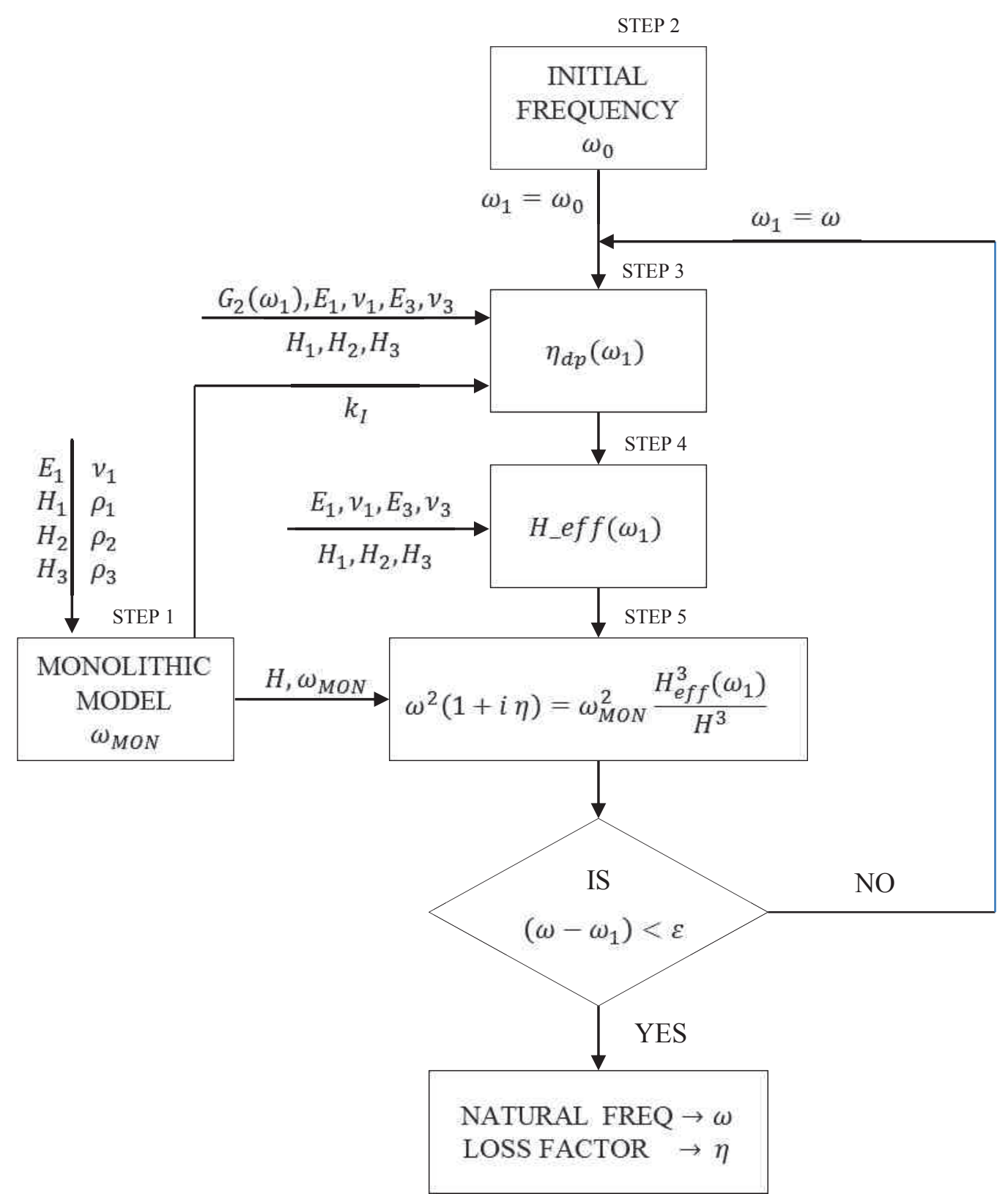




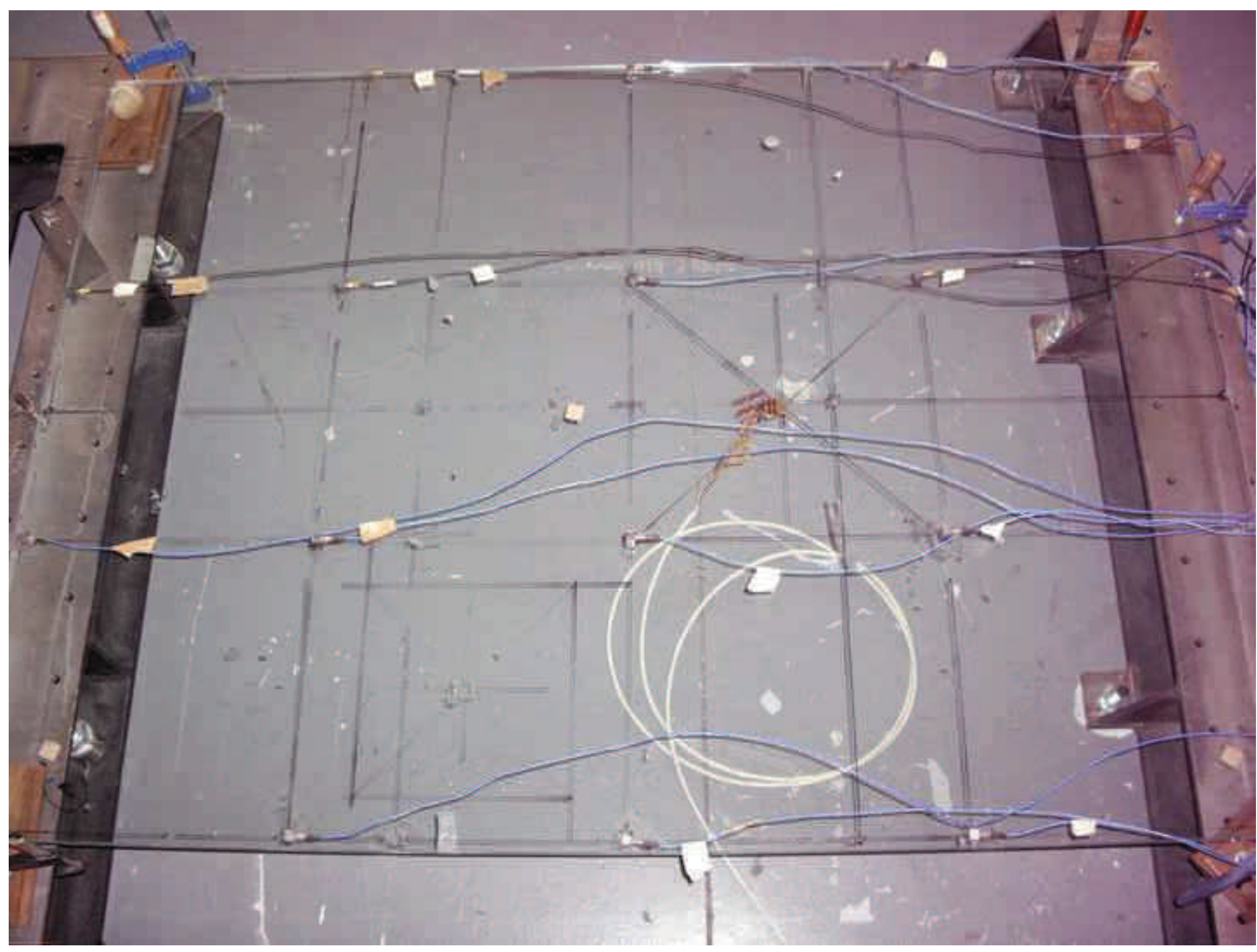


Figure5b

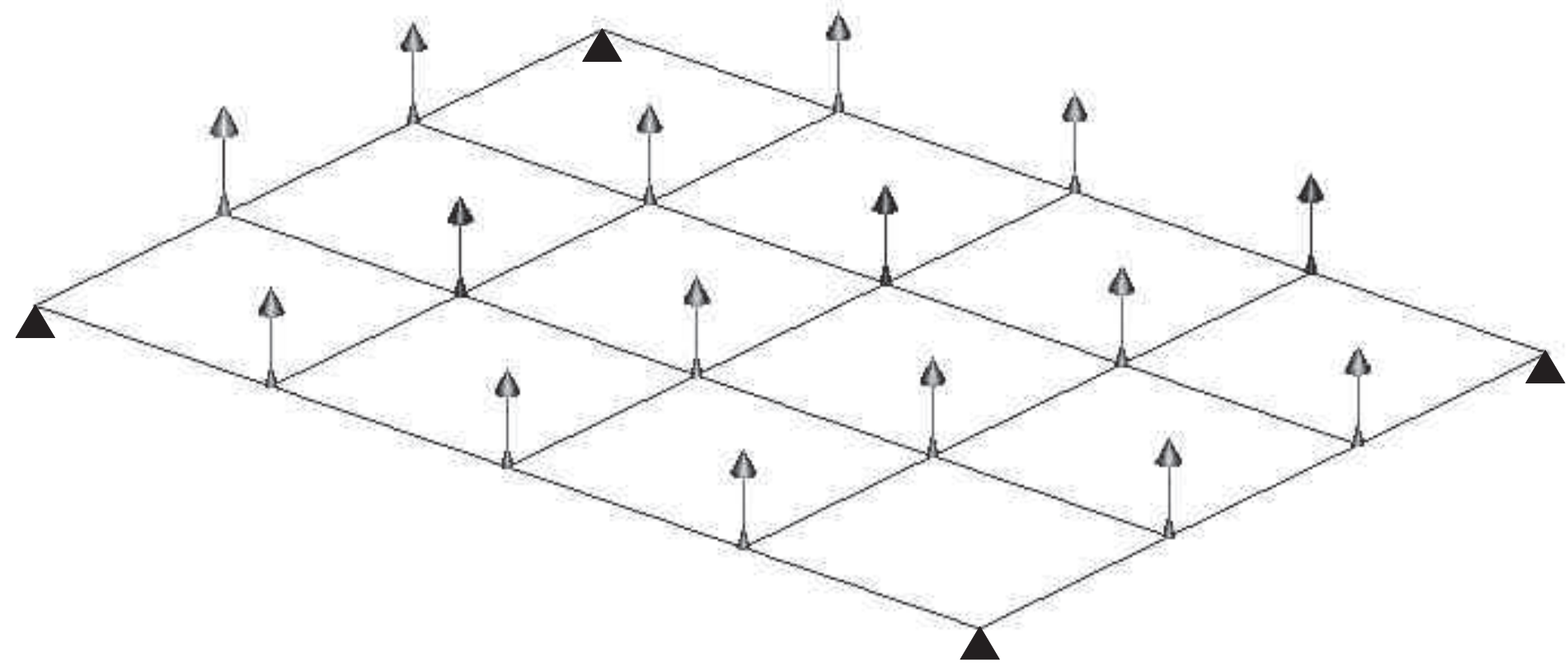




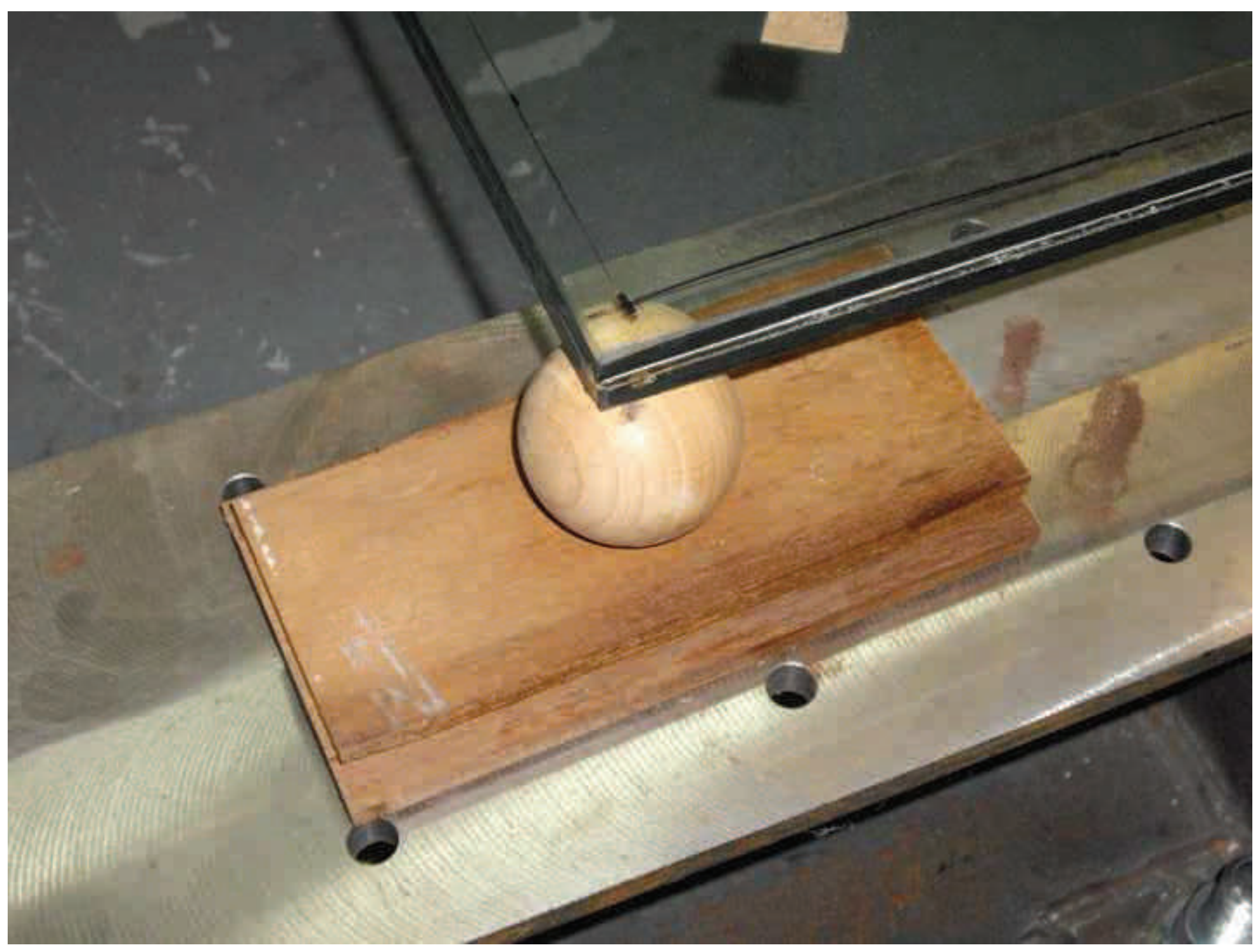




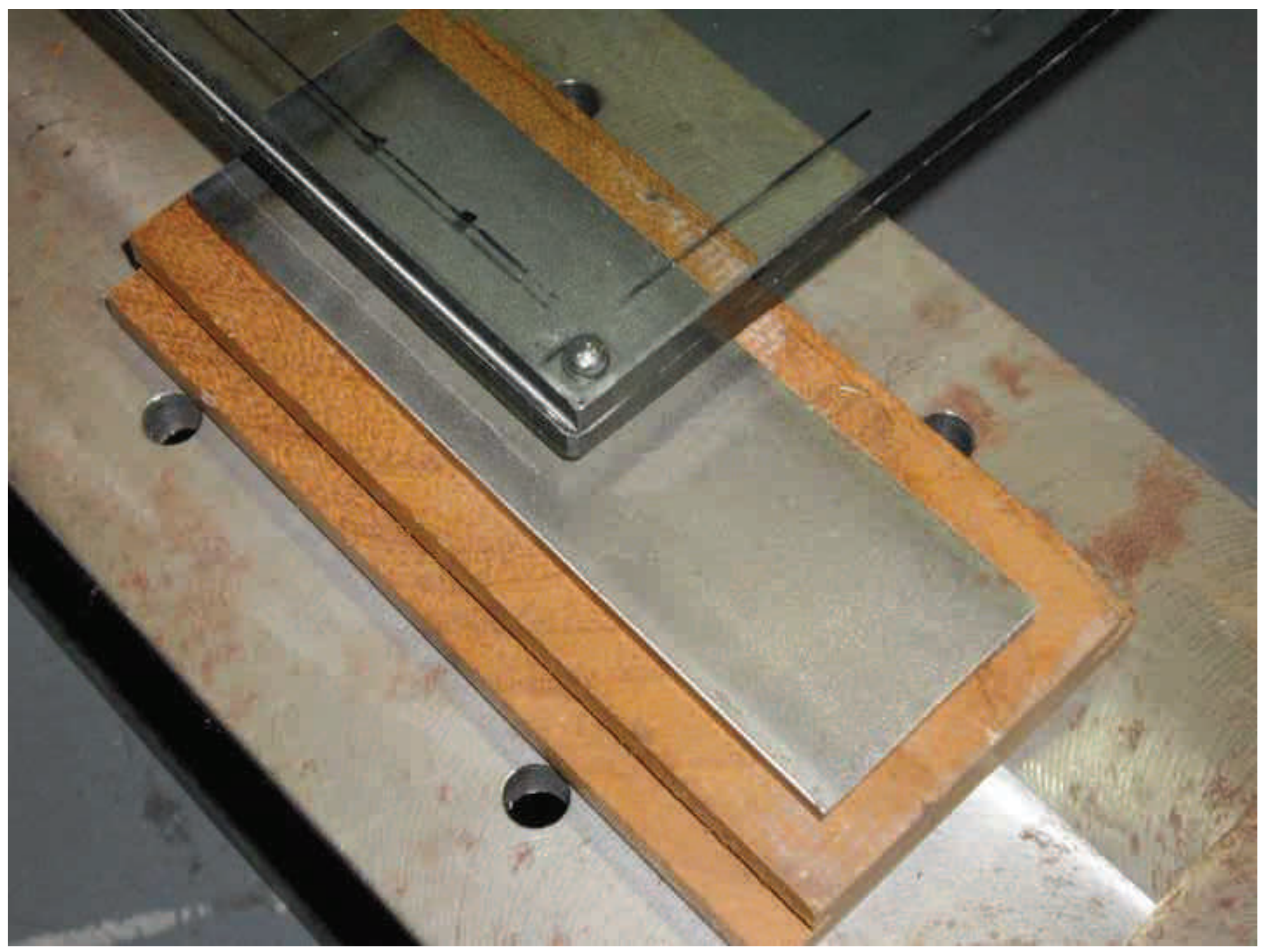


Figure7

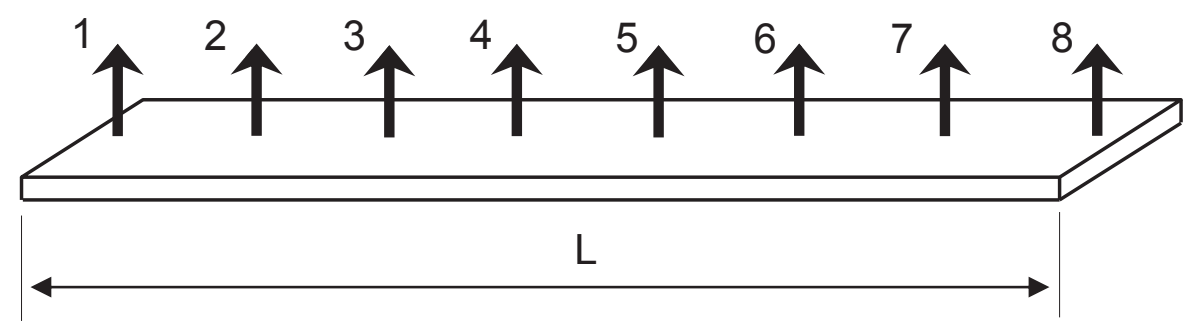



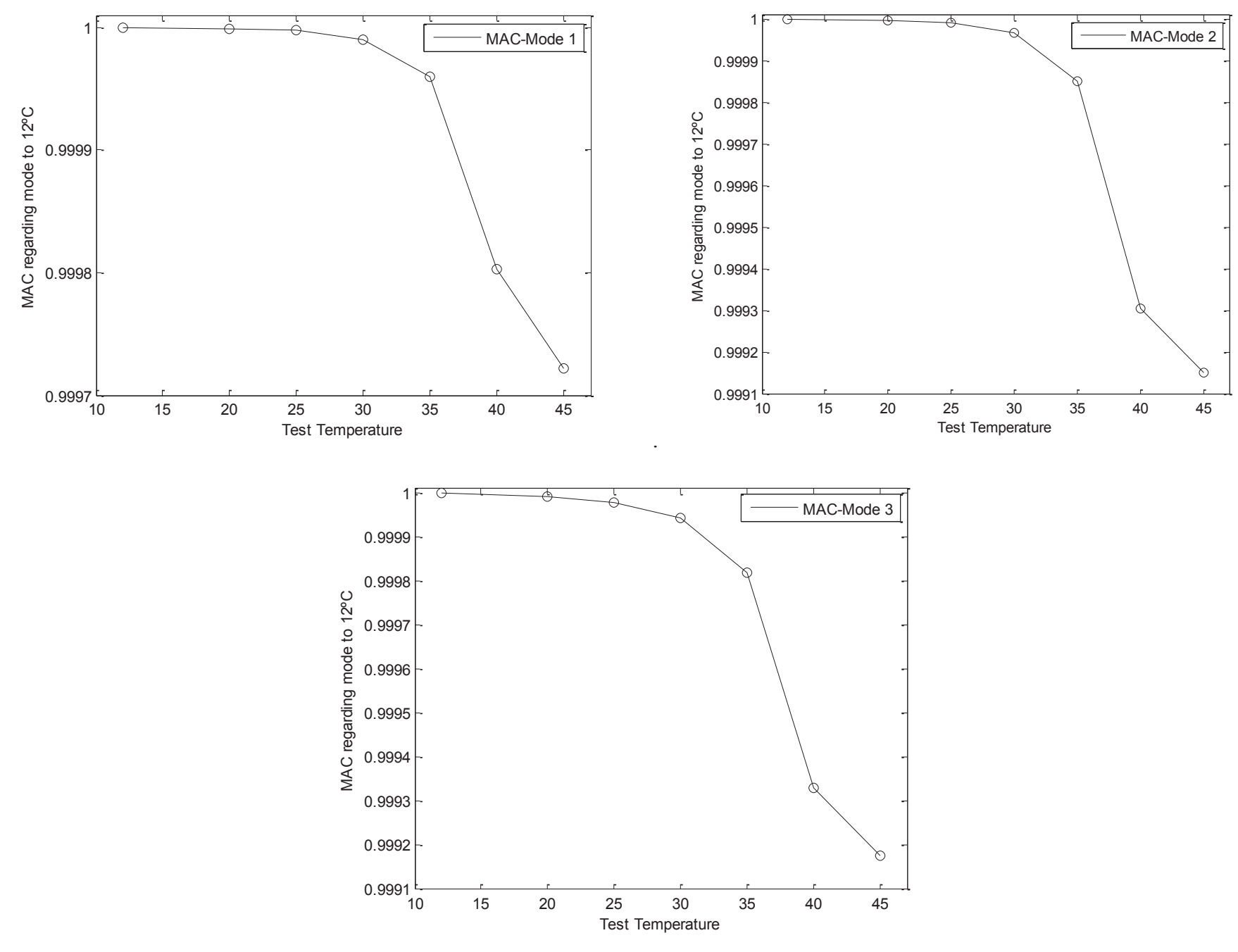

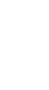

